\title{
The Role of Semaphorins and their Receptors in the Immune System and their Relation to Multiple Sclerosis
}

\author{
Ramin Lotfi ${ }^{1}$, Kheirollah Yari ${ }^{*}$ \\ ${ }^{1}$ Student Research Committee, School of Medicine, Kermanshah University of Medical Sciences, Kermanshah, Iran \\ ${ }^{2}$ Medical Biology Research Center, Kermanshah University of Medical Sciences, Kermanshah, Iran
}

\section{A BSTRACT}

Introduction: Semaphorins are large family of secretory and membrane-bound proteins that first were recognized in the nervous system as axon guidance molecules. Semaphorins family has more than 30 members and has been classified into eight subclasses. Different classes of these molecules involved in various phases of immune responses are considered as immune semaphorins. Main receptors for semaphorins are plexins and neuropilins. Moreover, other types of molecules can act as receptor for semaphorins, such as TIM-2 (T cell, immunoglobulin, and mucin domain protein 2) and CD72 that bind to Sema 4A (Semaphorin 4A), and Sema 4D. Both forms of semaphorins, namely secretory and membrane-bound semaphorins, play important roles in the immune system. Multiple sclerosis (MS), a chronic inflammatory autoimmune disease, is characterized by infiltration of lymphocytes into the central nervous system and demyelination. Recent investigations have shown that increased serum level or increased expression of some immune semaphorins is associated with severity of MS disease. Moreover, immune semaphorins-deficient mice are resistant to experimental autoimmune encephalomyelitis, which is attributed to impaired production of myelin basic protein-specific $\mathrm{T}$ cells. Conclusion: Identification of specific expression patterns of semaphorins and their receptors in the nervous system and a comprehensive understanding of their function in autoimmune brain disorders could provide a novel biomarker and therapeutic target for these disorders. The present study reviews the role of semaphorins and their receptors in the development and differentiation of immune cells and their relation to MS.

\section{Key words:}

1. Semaphorins

2. Immune System

3. Inflammation

4. Autoimmune Diseases

5. Multiple Sclerosis

*Corresponding Author: Kheirollah Yari

E-mail:kyari@kums.ac.ir 


\title{
نقش سمافورينها و گيرندهايشان در سيستهم ايمنى و ارتباط آنها با بيمارى مالتييل اسكلروز
}

\author{
رامين لطفى'، خير اله يارى ب٪. \\ 'كميتهُ تحقيقات دانشجويى، دانشكده يزشكى، دانشكاه علوم يزشكى كرمانشاه، كرمانشاه، ايران \\ 'مركز تحقيقات بيولوزى يزشكى، دانشخاه علوم يزشكى كرمانشاه، كرمانشاه، ايران
}

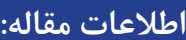

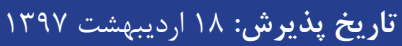

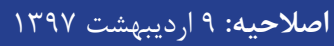

تاريخ دريافت: V بهمن عqسا

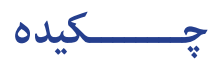

مقدمه: سمافورينها خانوادهاى بزرى از يروتئينهاى ترشحى و متصل به غشاء هستند كه ابتدا در

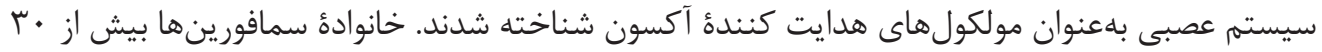

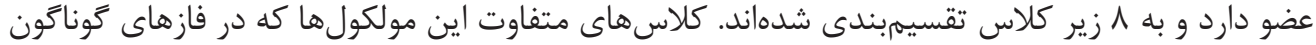

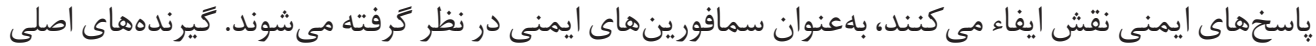

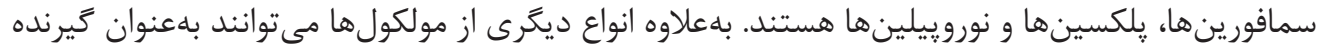

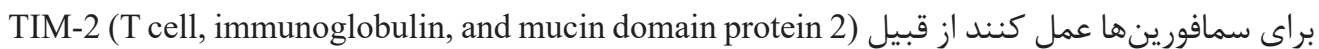

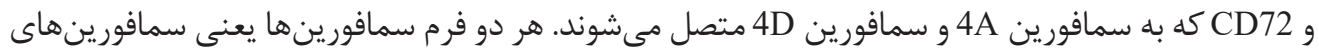

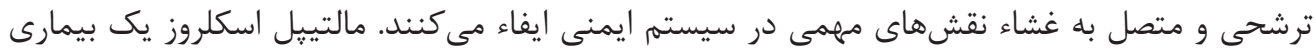

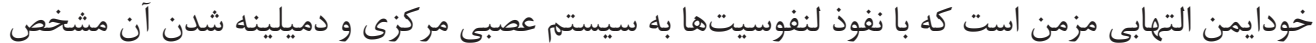

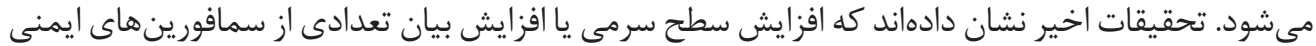

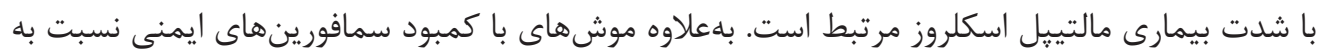

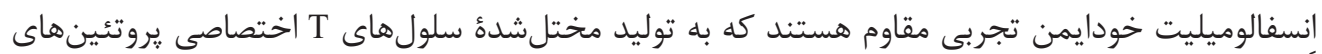

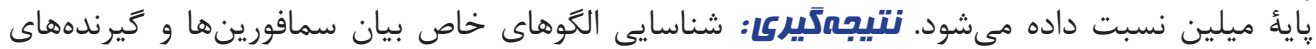

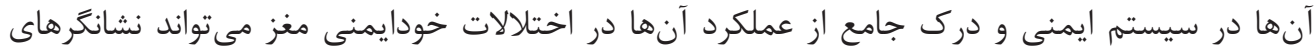

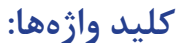

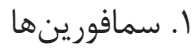

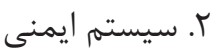

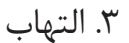

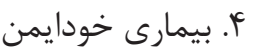
ه. مالتيبِ اسكلروز

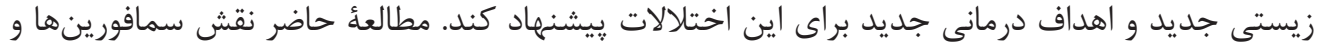

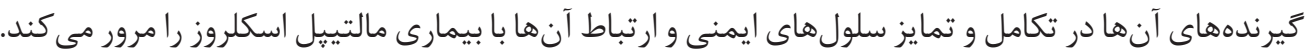

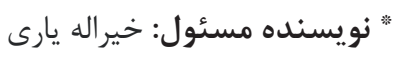

آدرس الكترونيكى: kyari@kums.ac.ir 


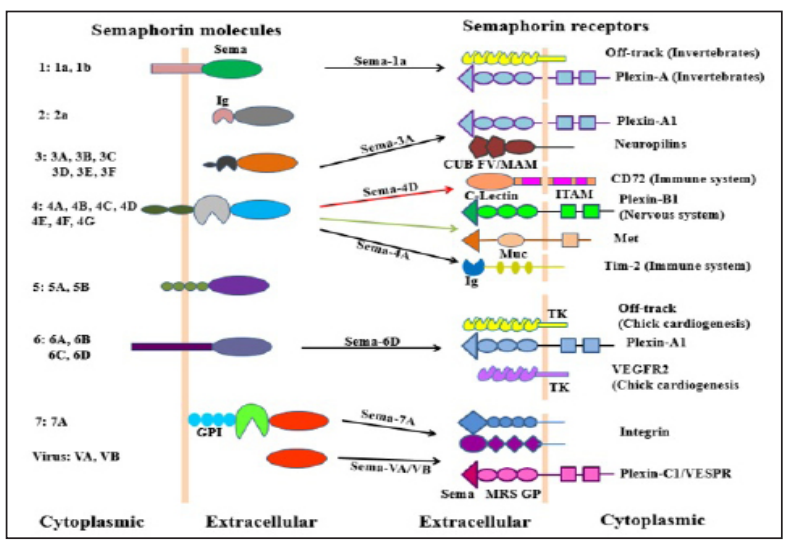

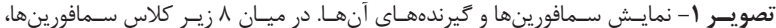

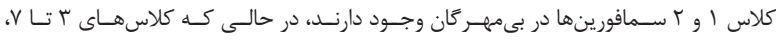

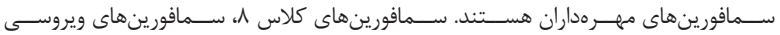

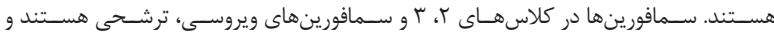

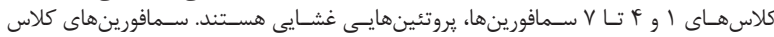

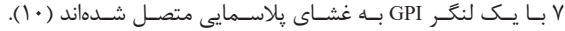

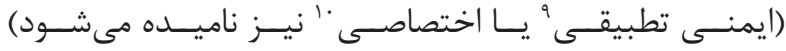

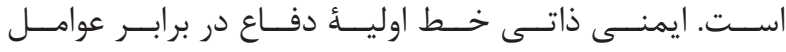

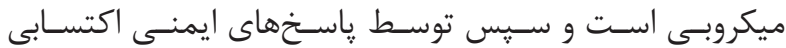

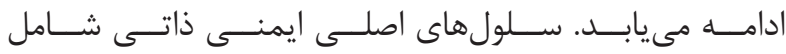

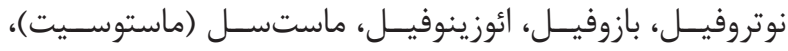

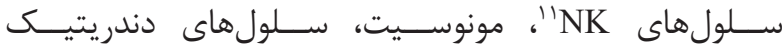

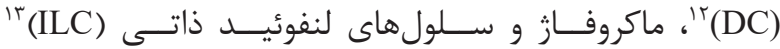

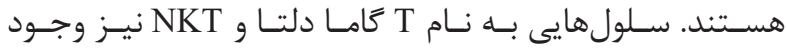

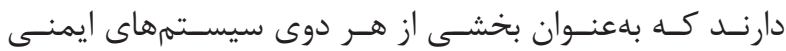

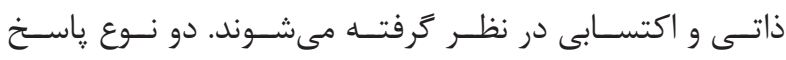

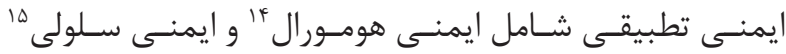

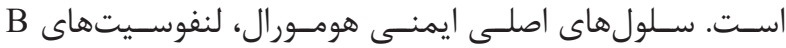

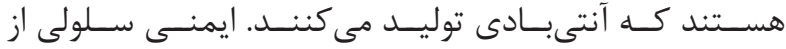

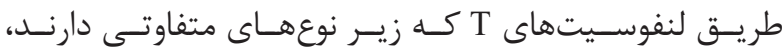

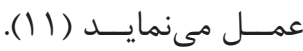

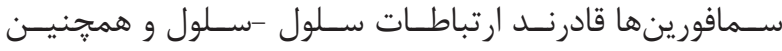

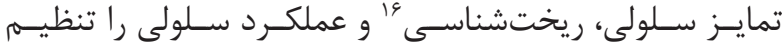

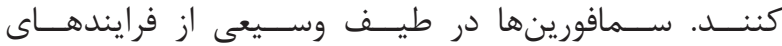

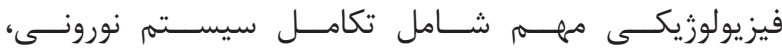

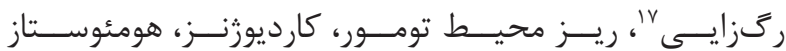

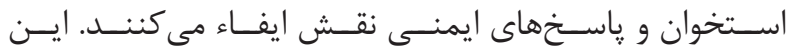

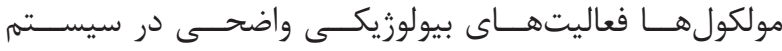

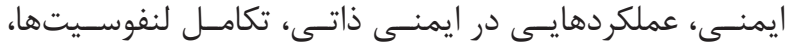

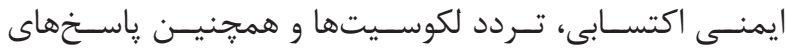

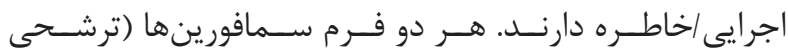

${ }^{1}$ Semaphorins

${ }^{2}$ Signaling

${ }^{3}$ Glycophosphatidylinositol

${ }^{4}$ Plexin

${ }^{5}$ Neuropilin

${ }^{6}$ Receptors

${ }^{7}$ Innate immunity

${ }^{8}$ Acquired immunity

${ }^{9}$ Adaptive

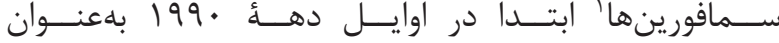

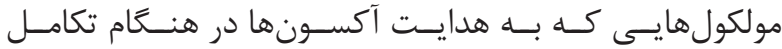

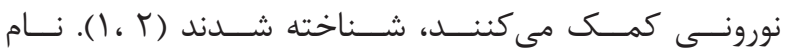

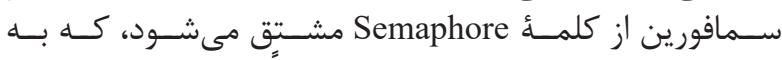

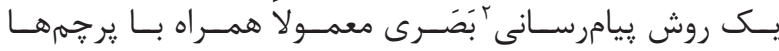

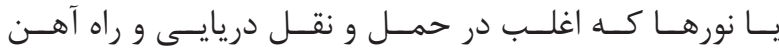

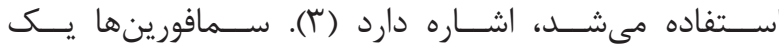

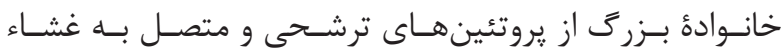

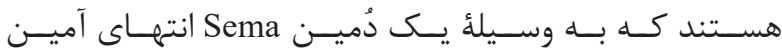

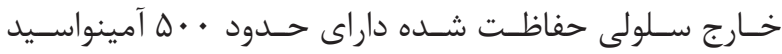

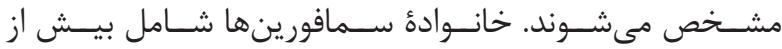

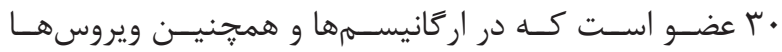

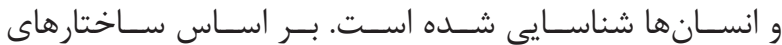

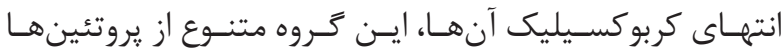

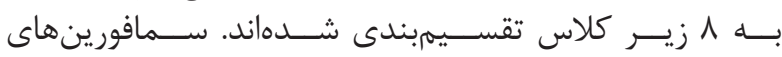

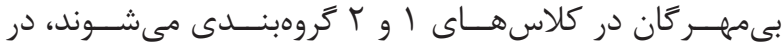

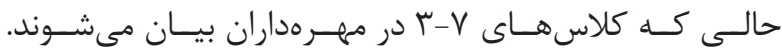

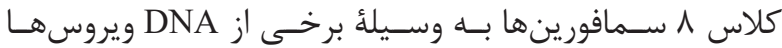

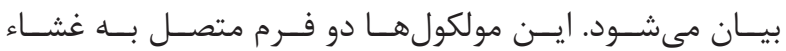

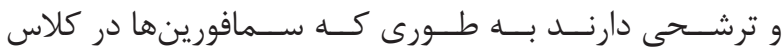

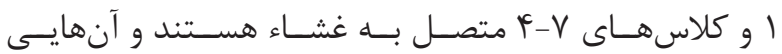

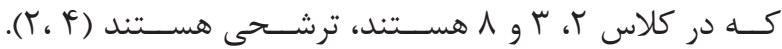

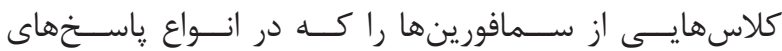

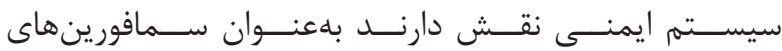

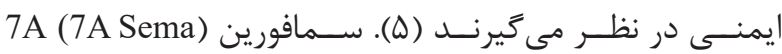

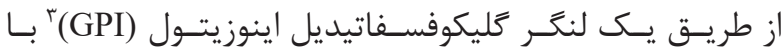

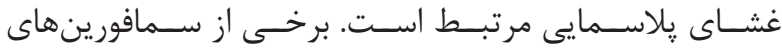

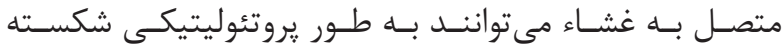

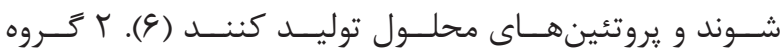

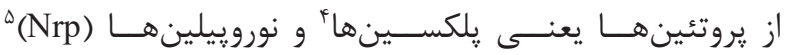

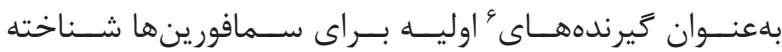

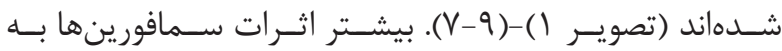

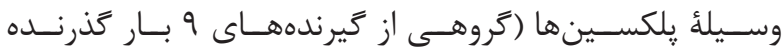

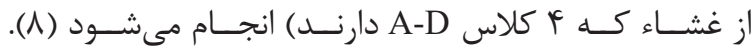

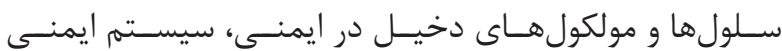

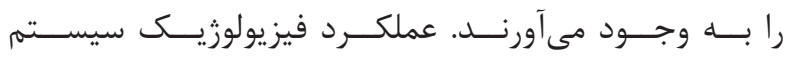

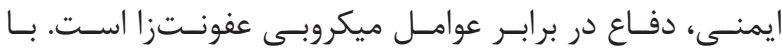

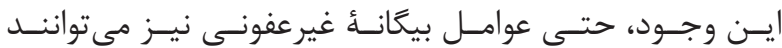

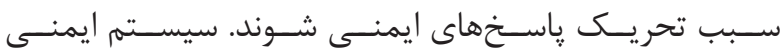

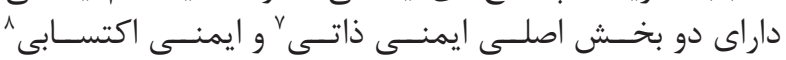

\footnotetext{
${ }^{10}$ Specific

${ }^{11}$ Natural killer cell

${ }^{12}$ Dendritic cell

${ }^{13}$ Innate lymphoid cell

${ }^{14}$ Humoral

${ }^{15}$ Cell-mediated or cellular

${ }^{16}$ Morphology

${ }^{17}$ Angiogenesis
} 
توســط فاكتــور رونويســى CIITA

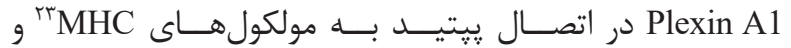

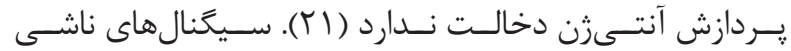

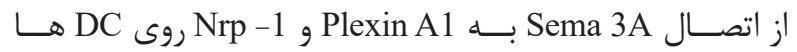

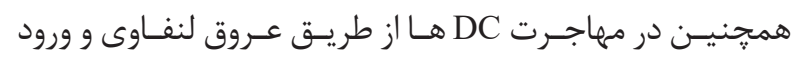

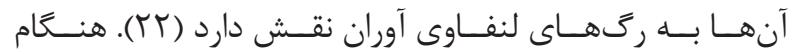

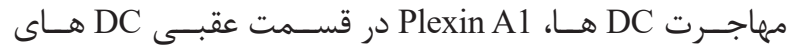

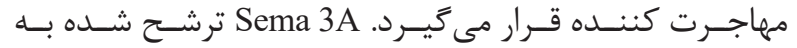

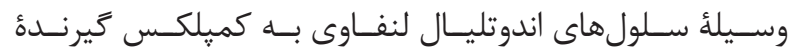

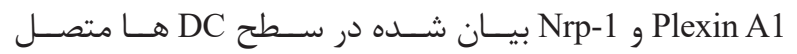

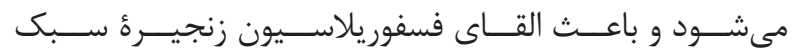

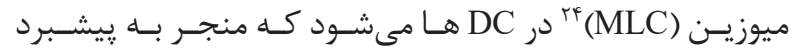

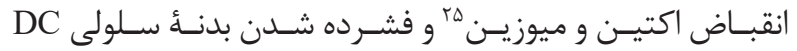

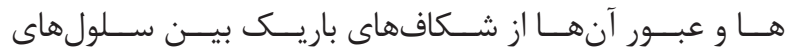

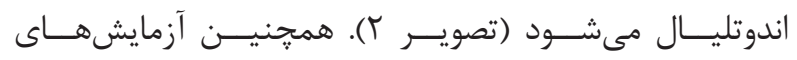

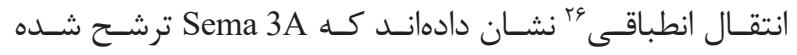

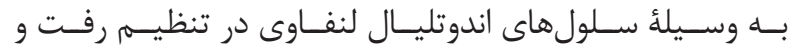

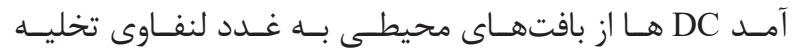

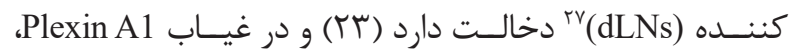

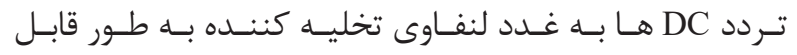

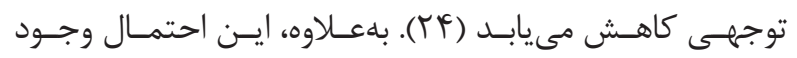

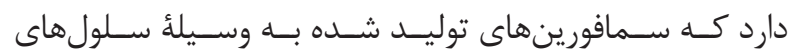

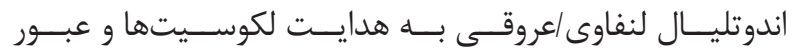

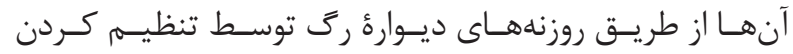

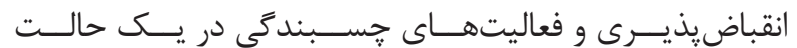

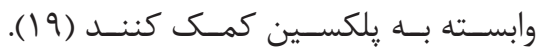

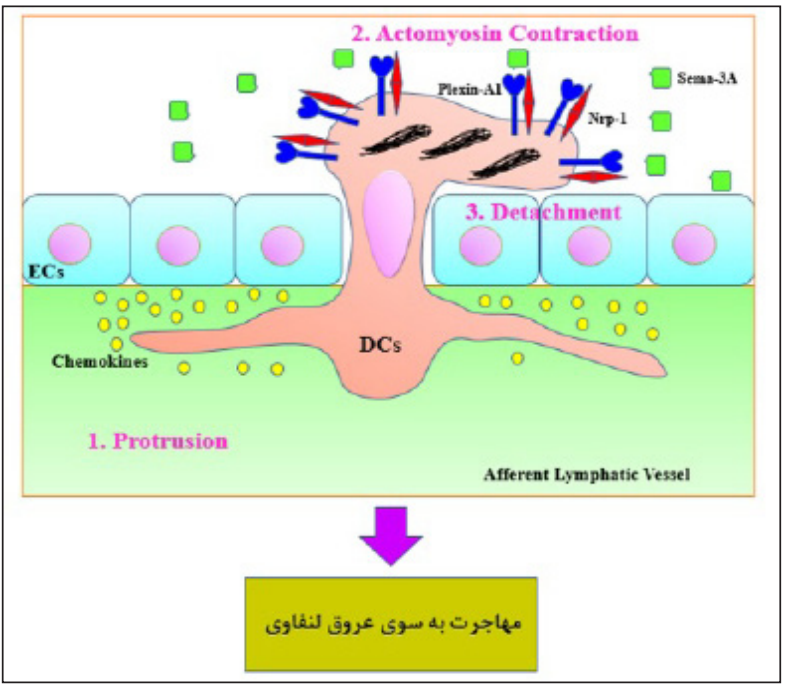

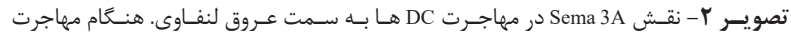

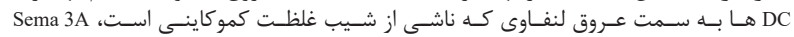

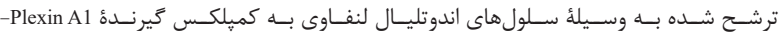

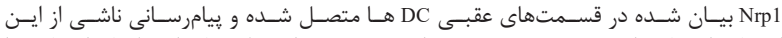

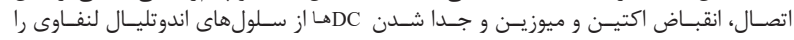

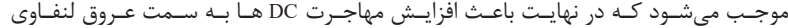

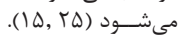

${ }^{18}$ Transmigration

${ }^{19} \mathrm{~T}$ cell, immunoglobulin, and mucin domain protein

${ }^{20}$ Multiple sclerosis

${ }^{21}$ RNA interference

${ }^{22}$ Class II transactivator

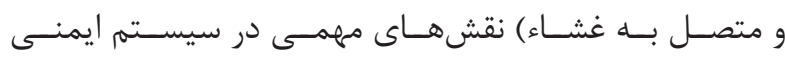

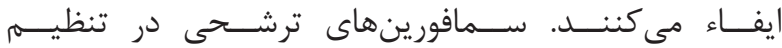

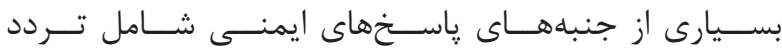

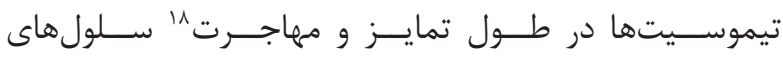

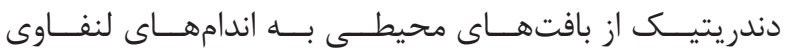

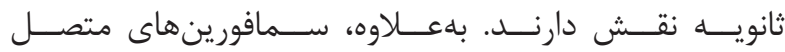

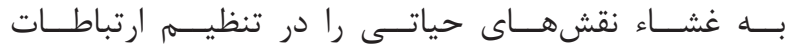

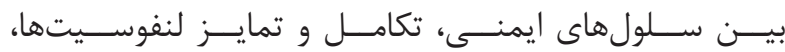

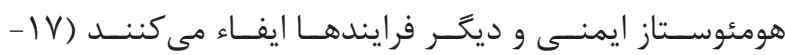

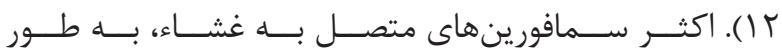

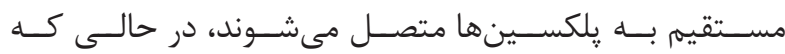

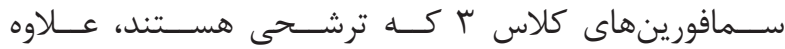

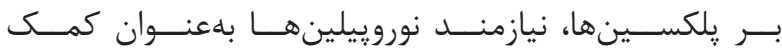

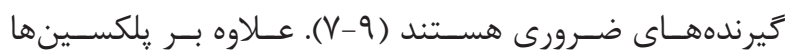

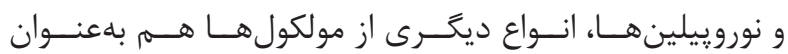

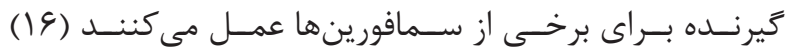

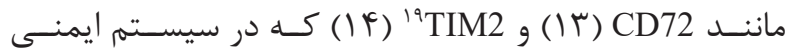

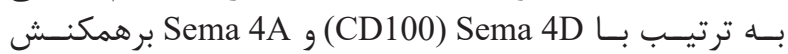

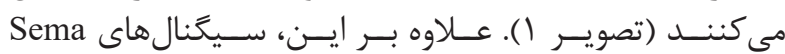

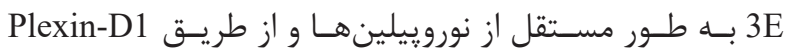

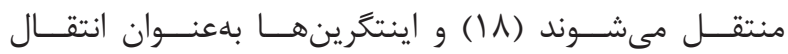

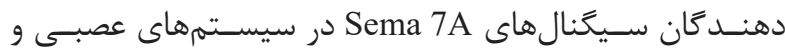

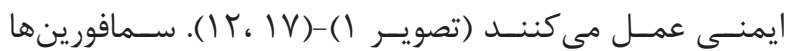

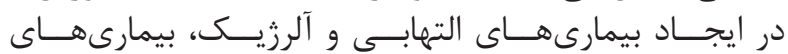

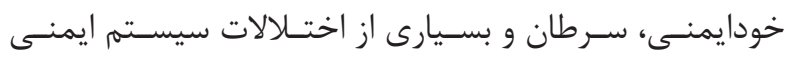

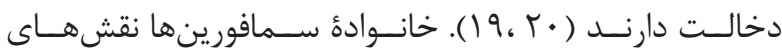

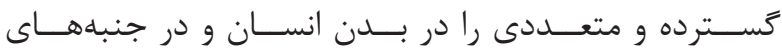

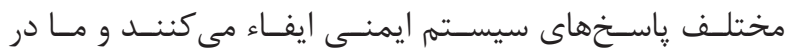

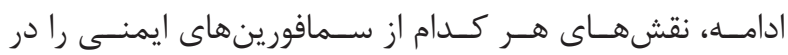

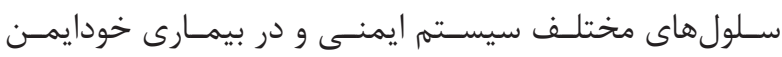

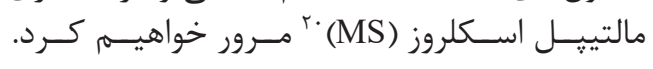

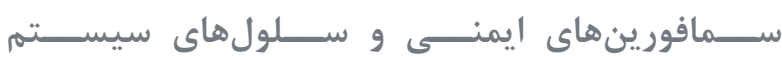
ايمنــى ذاتسى إنى

\section{Sema 3A}

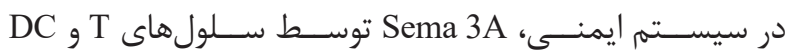

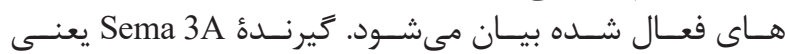

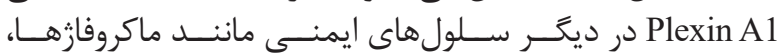

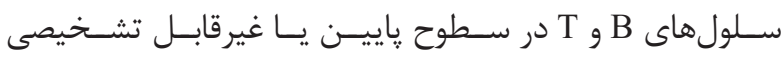

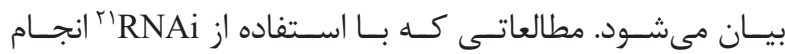

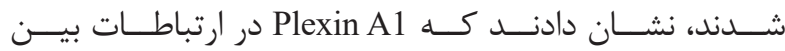

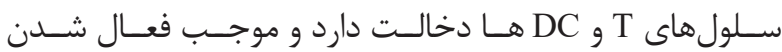

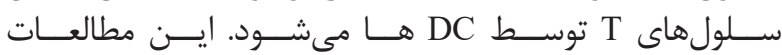

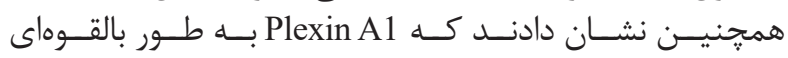

\footnotetext{
${ }^{23}$ Major histocompatibility complex

${ }^{24}$ Myosin light-chain

${ }^{25}$ Actomyosin

${ }^{26}$ Adoptive-transfer

${ }^{27}$ Draining lymph nodes
} 


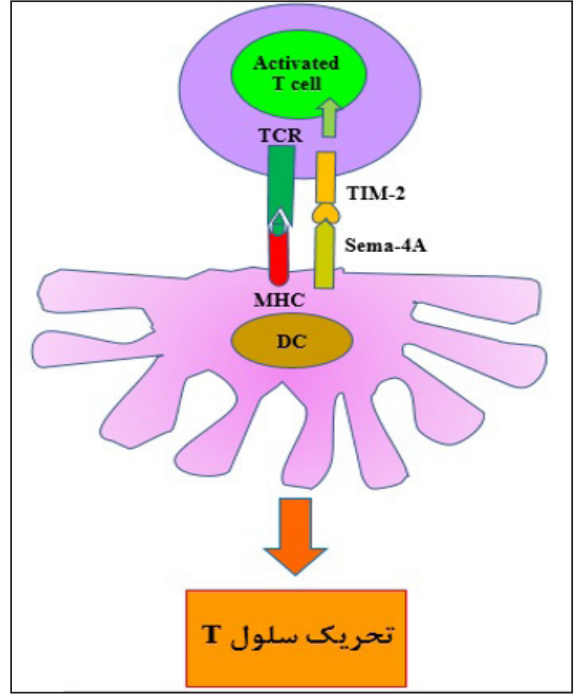

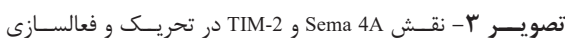

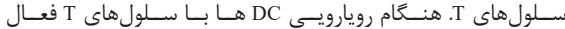

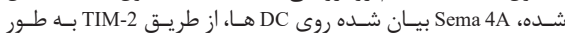

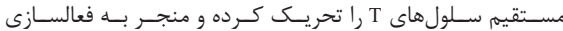

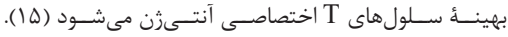

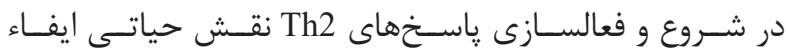

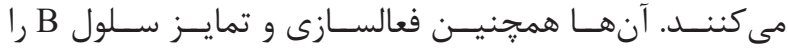

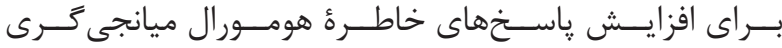

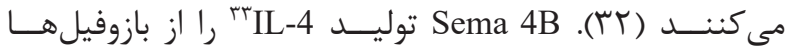

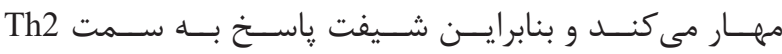

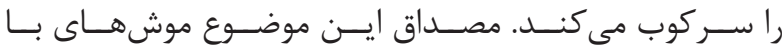

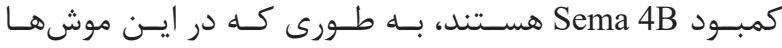
توليـــ IgE

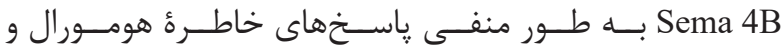

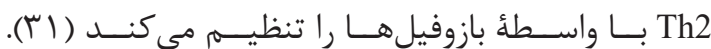

\section{(CD100) Sema 4D}

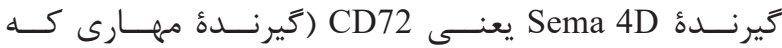

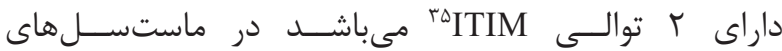

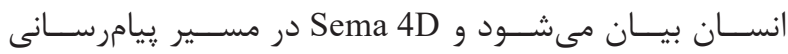

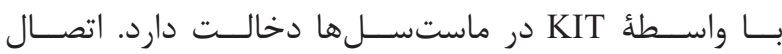

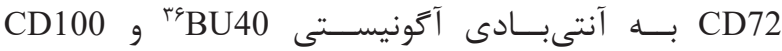

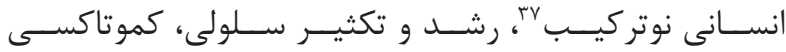

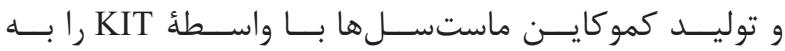

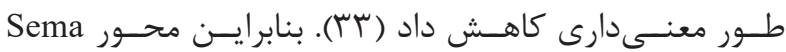

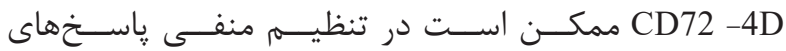

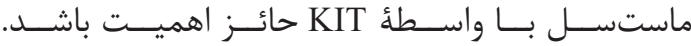

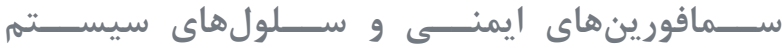

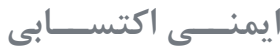

${ }^{28}$ Mitogen-activated protein kinases

${ }^{29} \mathrm{~T}$ helper 1

${ }^{30} \mathrm{~T}$ cell mediated immune responses

${ }^{31} \mathrm{~T}$ cell, immunoglobulin, and mucin domain protein 2

${ }^{32}$ Antigen presenting cell

\section{Sema 3A}

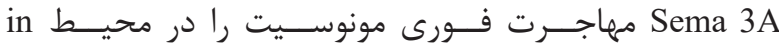

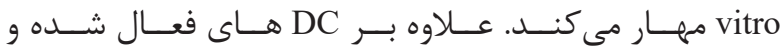

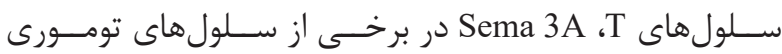

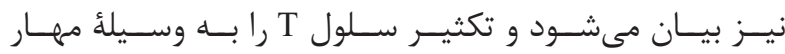

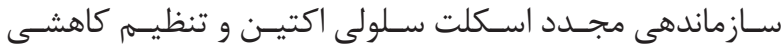

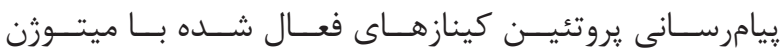
(MAPKs)

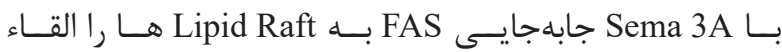

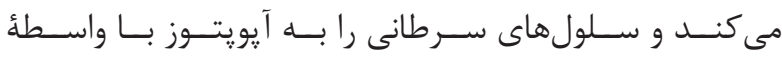

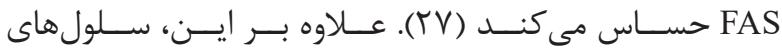

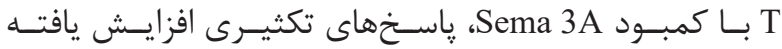

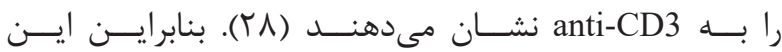

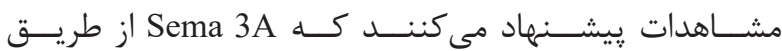

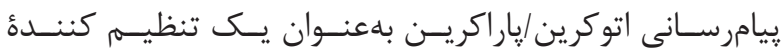

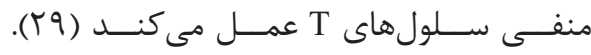

\section{DC و عملكردهاى Sema 4A}

Sema 4A

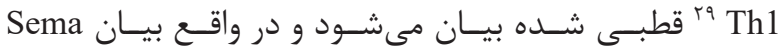

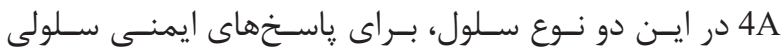
(TCMIRs)

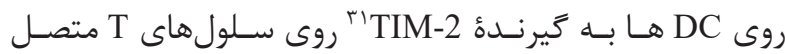

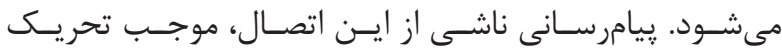

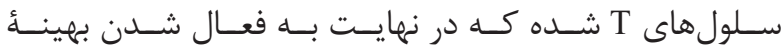

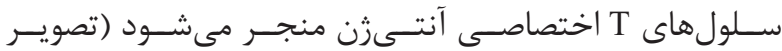

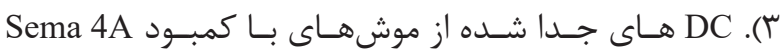

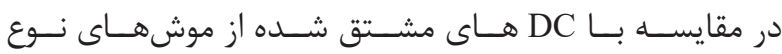

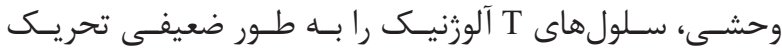

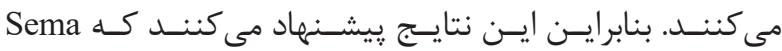

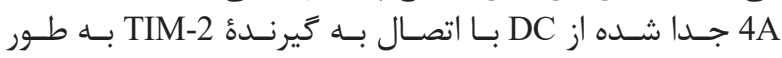

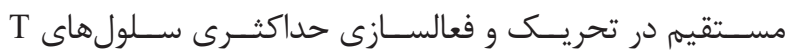

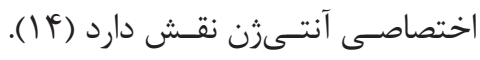

\section{Sema 4B}

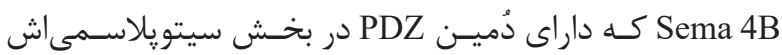

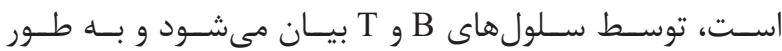

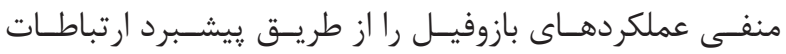

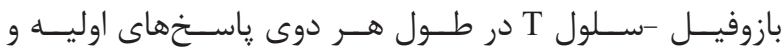

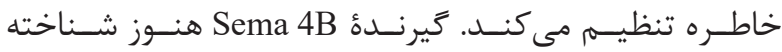

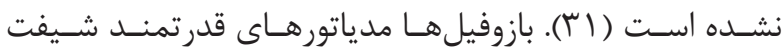

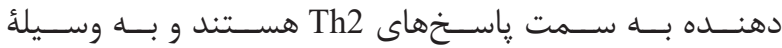

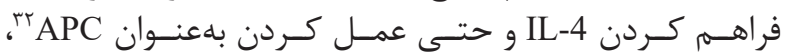

\footnotetext{
${ }^{33}$ Interleukin 4

${ }^{34}$ Immunoglobulin E

${ }^{35}$ Immunoreceptor tyrosine-based inhibitory motif

${ }^{36}$ anti-CD72 antibody

${ }^{37}$ rCD100: recombinant CD100
} 


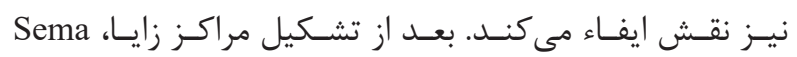

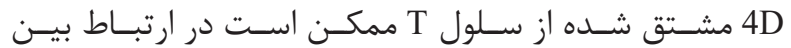

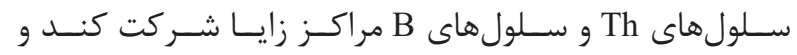

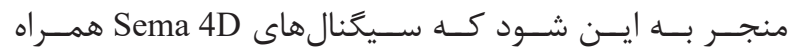

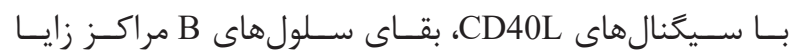

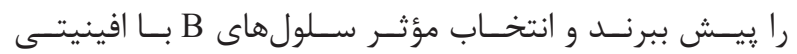

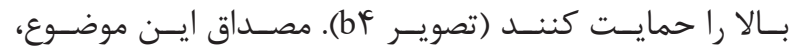

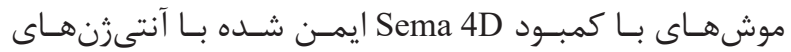

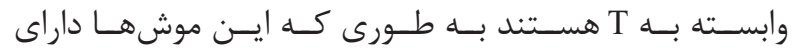

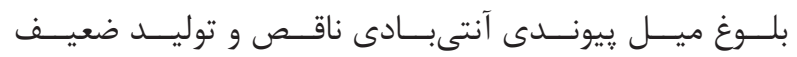

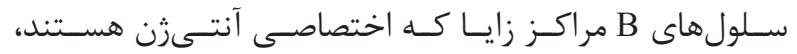

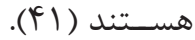

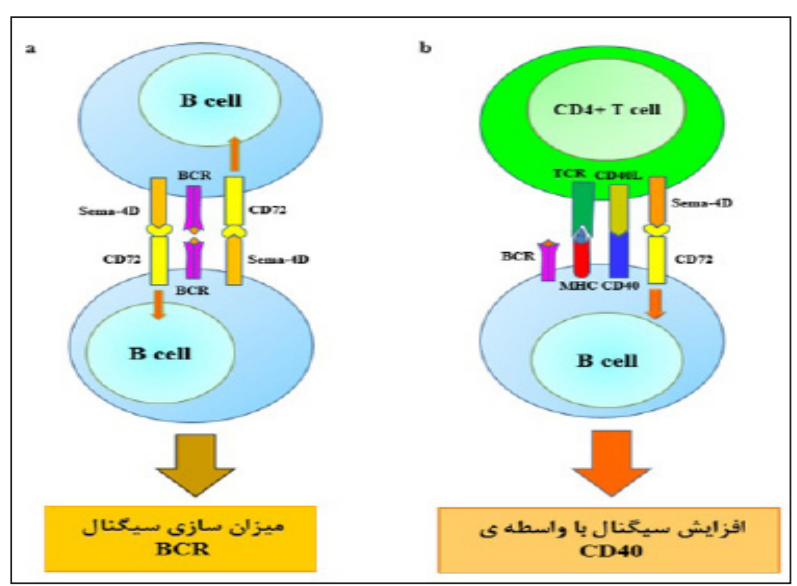

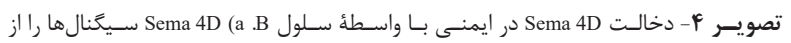

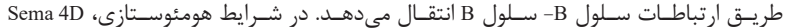

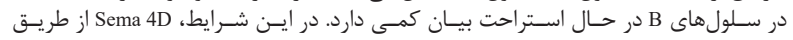

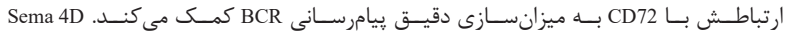

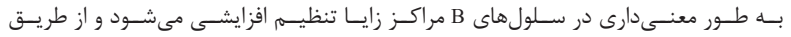

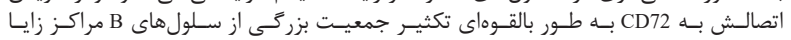

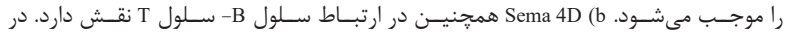

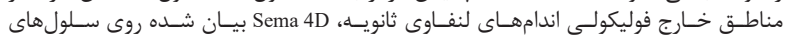

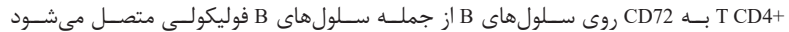

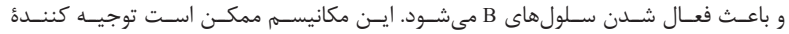

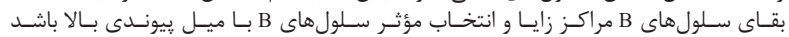

\section{Sema 4C و پِاريزاسيون سلول B}

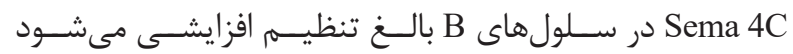

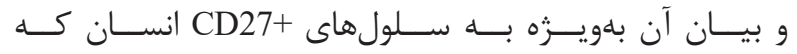

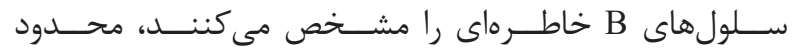

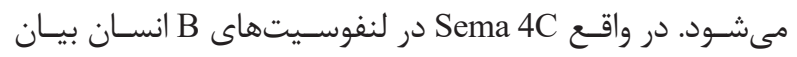

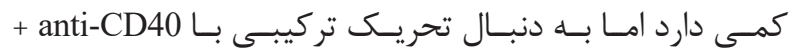

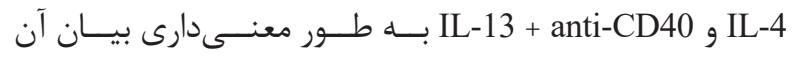

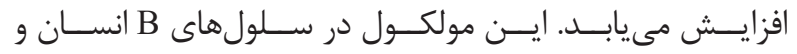

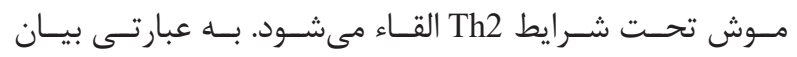

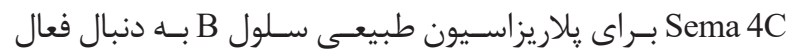

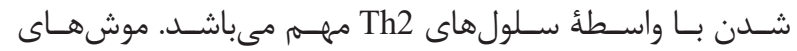

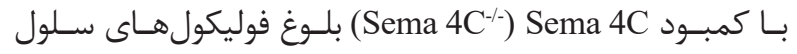

${ }^{38}$ Lipopolysaccharide

${ }^{39}$ anti-CD40

${ }^{40} \mathrm{SH} 2$ (Src homology 2) domain-containing protein tyrosine phosphatase-1

\section{S و عملكر دهاى لنفوسيت Sema 4D}

Sema 4D

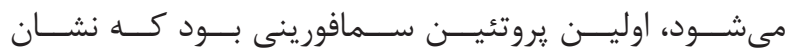

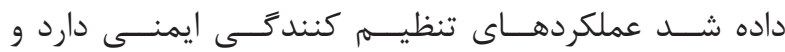

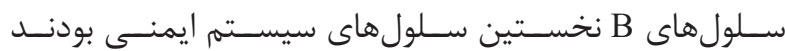

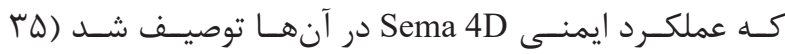

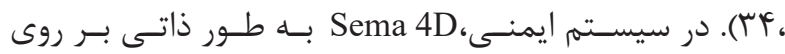

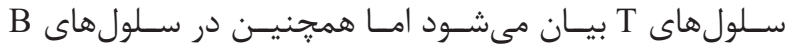

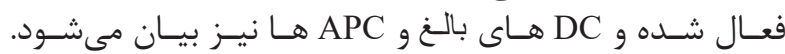

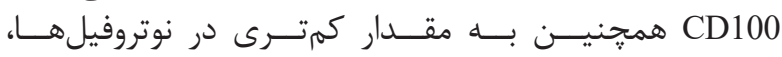

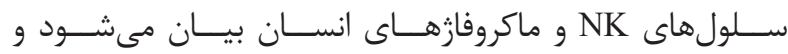

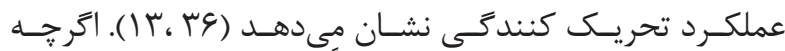

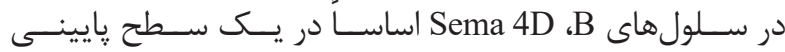

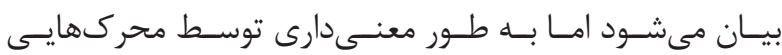

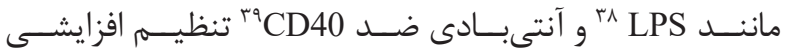

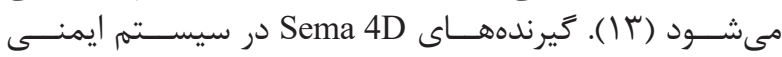

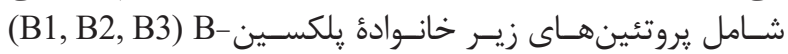

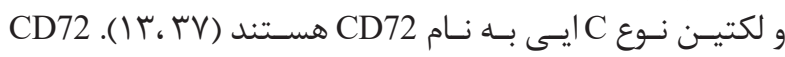

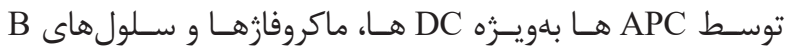

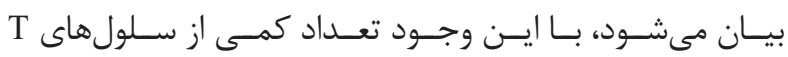

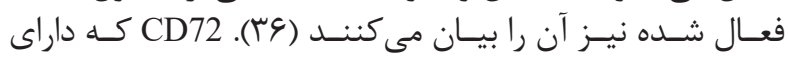

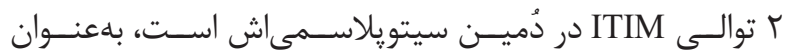

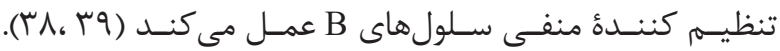

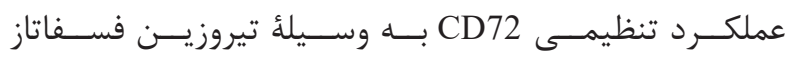

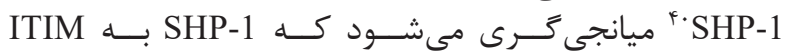

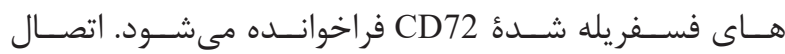

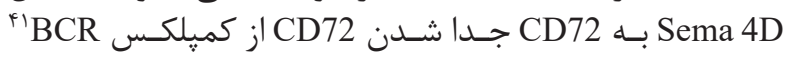

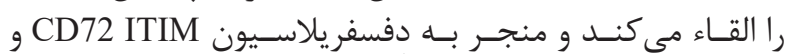

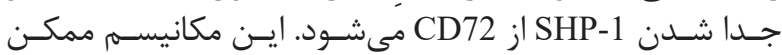

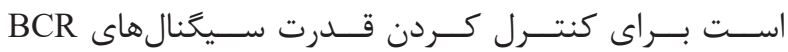

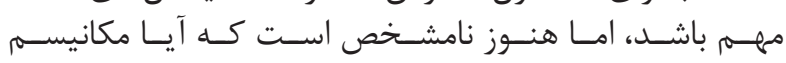

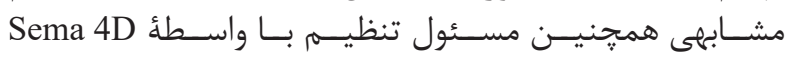

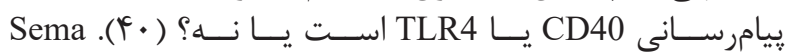

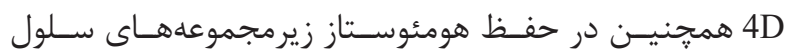

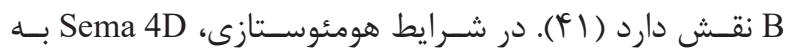

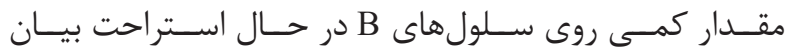

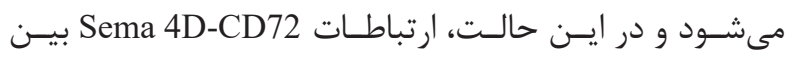

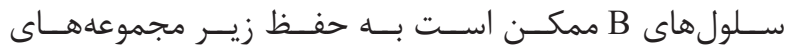

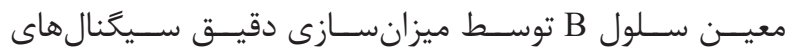

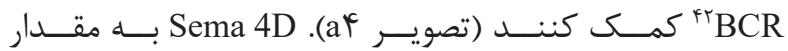

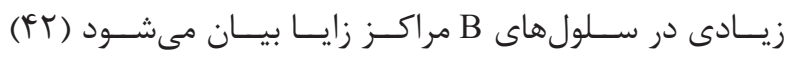

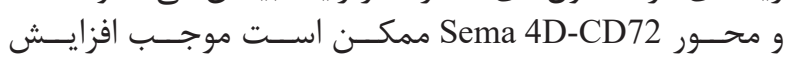

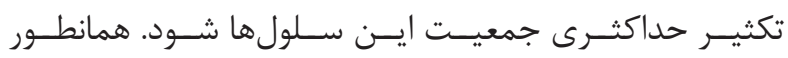

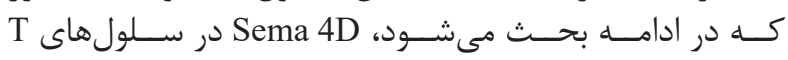

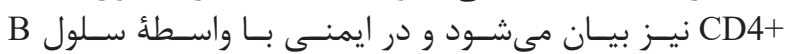

${ }^{41} \mathrm{~B}$ cell receptor

${ }^{42}$ BCR signal tuning 


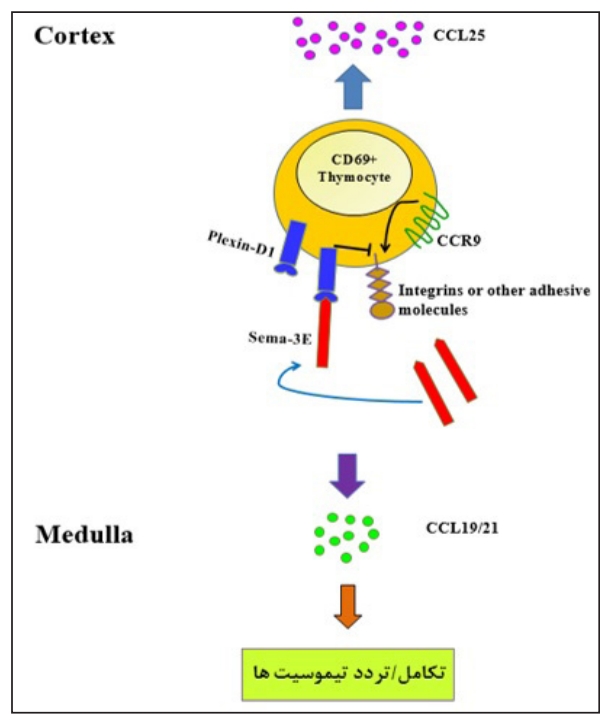

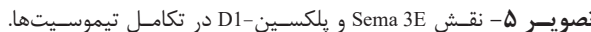
ترشح شـــ Sema 3E

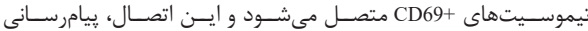

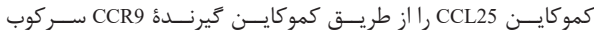

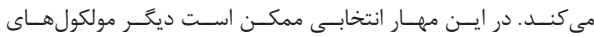

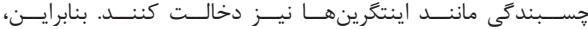

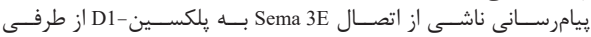

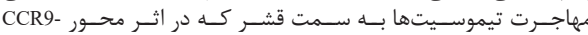

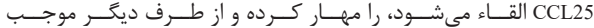

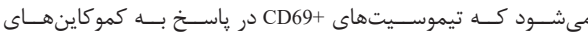

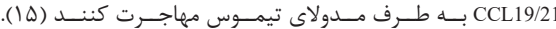

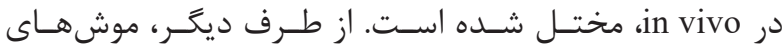

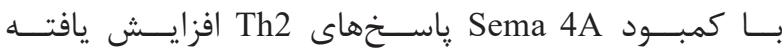

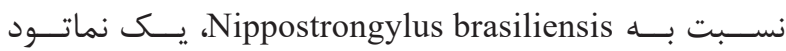

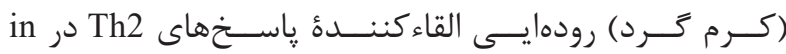

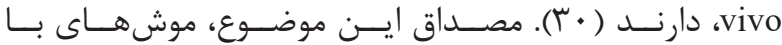

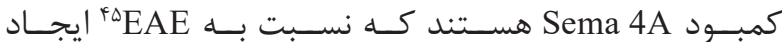

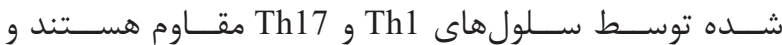

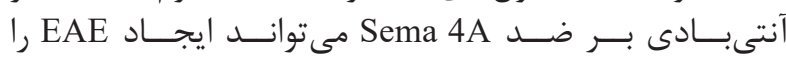

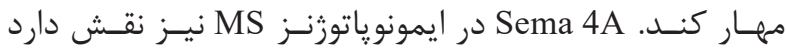

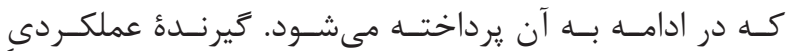

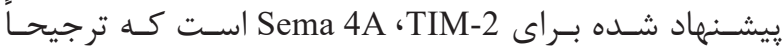

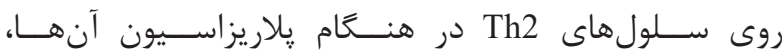

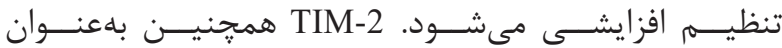

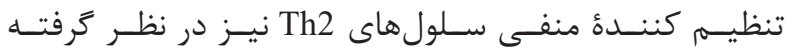

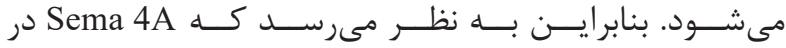

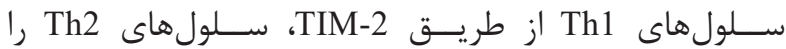

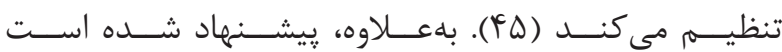

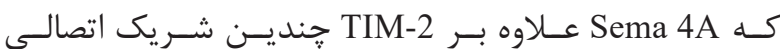

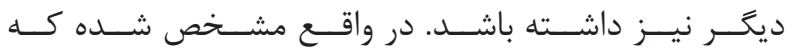

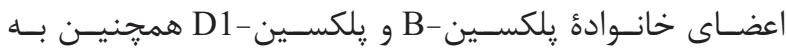
Sema 4A

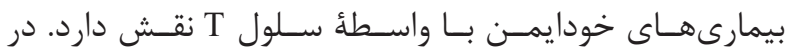

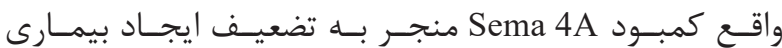

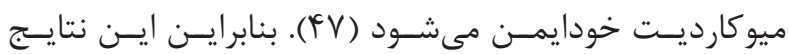

${ }^{43}$ Marginal zone B cells

${ }^{44}$ Follicular B cells

${ }^{45}$ Experimental autoimmune encephalomyelitis

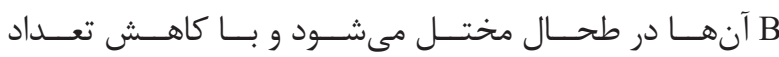

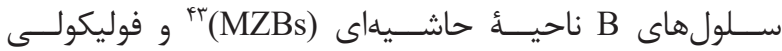
(FOBs)

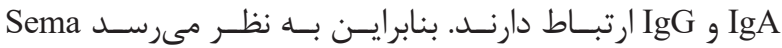

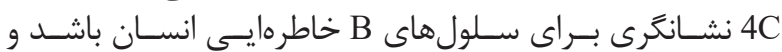

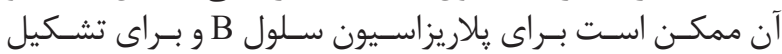

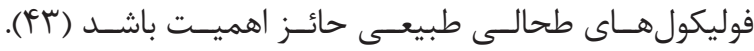

Sema 3E

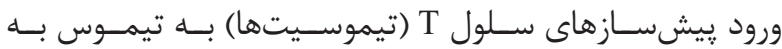

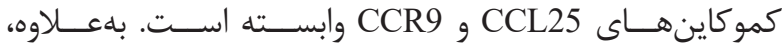

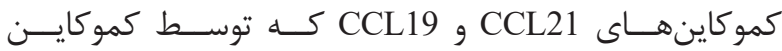

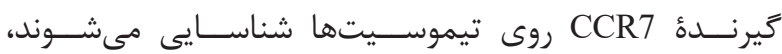

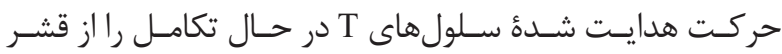

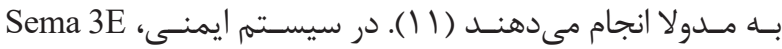

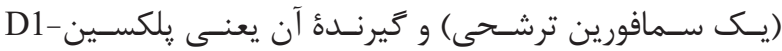

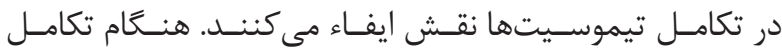

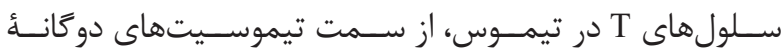

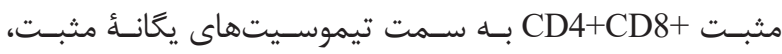

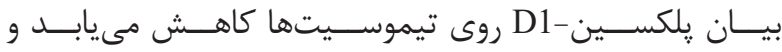
Sema 3E

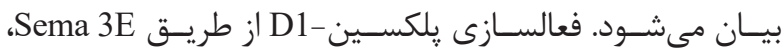

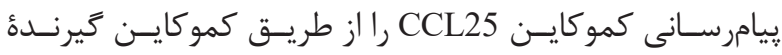
CCR9

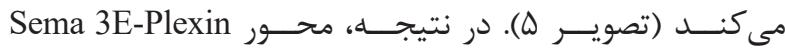

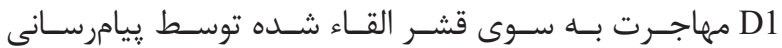

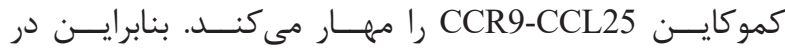

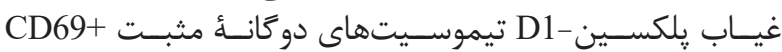

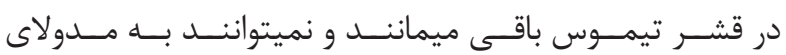

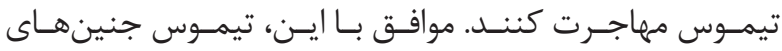

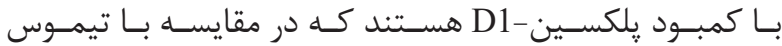

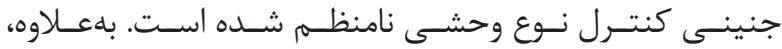

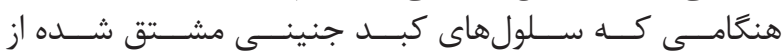

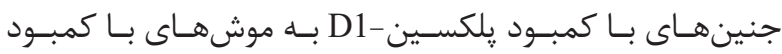

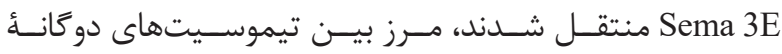

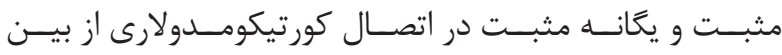

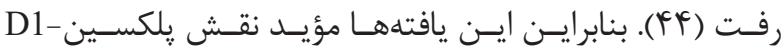

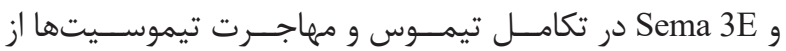

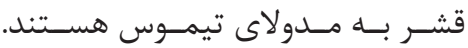

\section{T و عملكرد سلول Sema 4A}

بـانهـ طـور ذاتـى در سـلولهاى Th1 قطبــى شـده

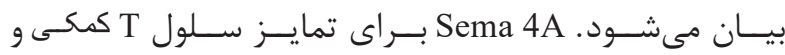

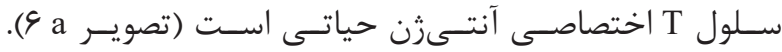

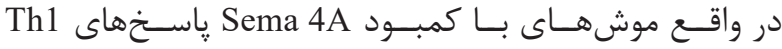

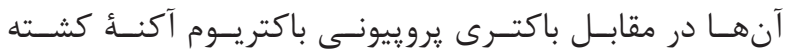

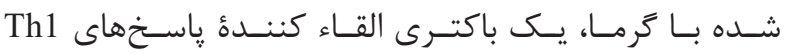


Sema 4D و ايمنى با واسطُ سلول T

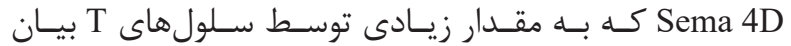

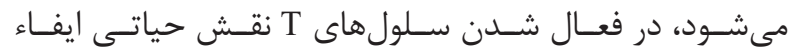

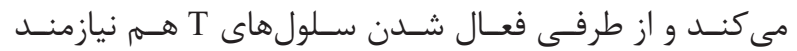

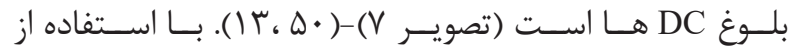

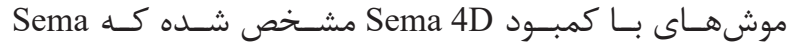

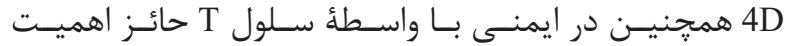

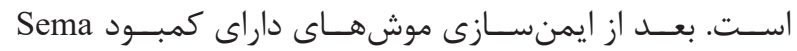

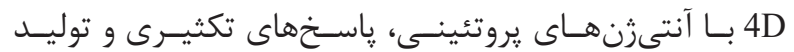

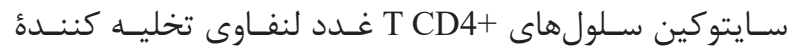

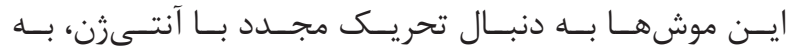

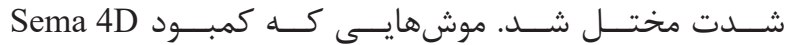

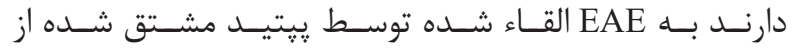

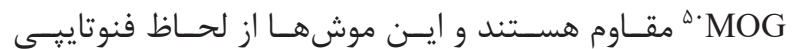

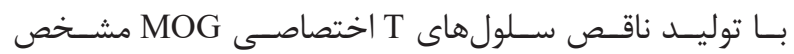

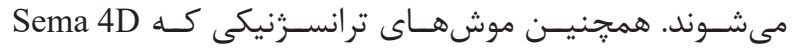

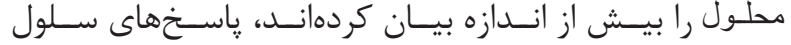

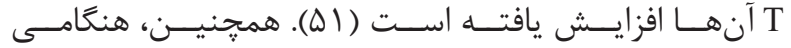

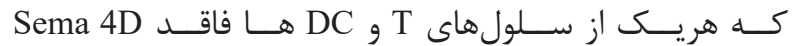

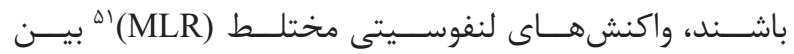

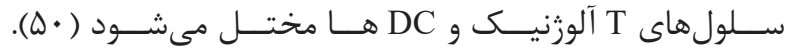

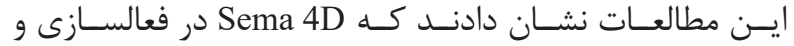

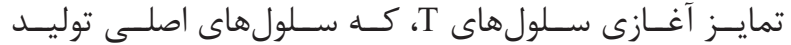

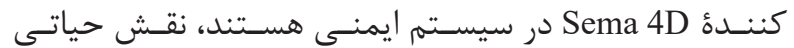

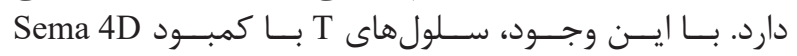

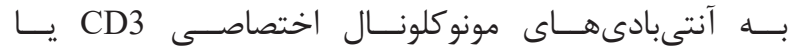

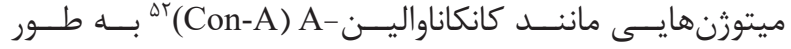

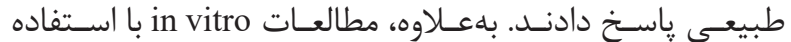

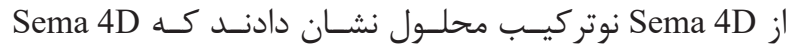

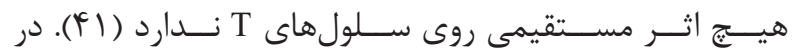

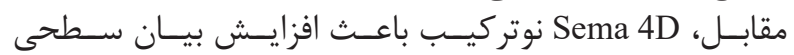

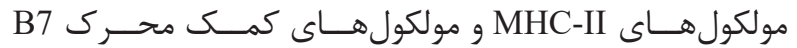

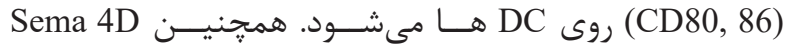

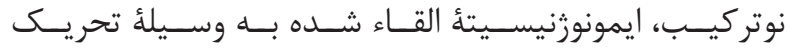

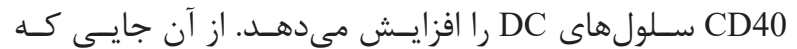

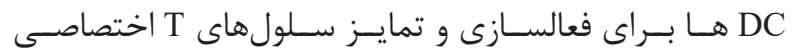

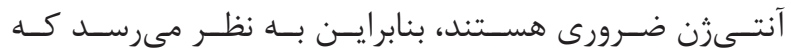

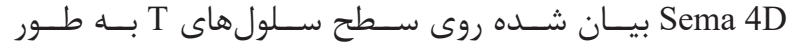

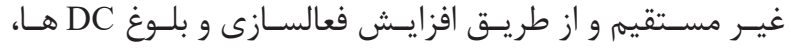

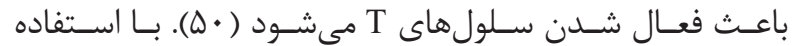

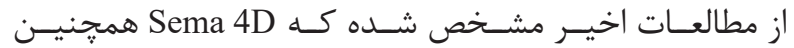

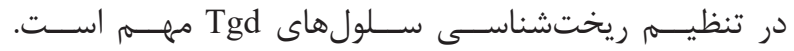

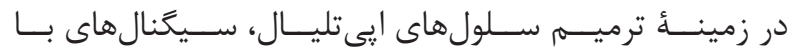

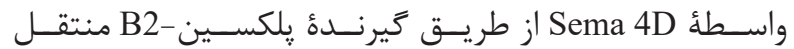

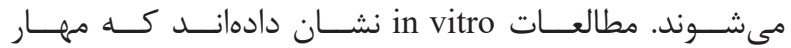

${ }^{46}$ Regulatory T cells

${ }^{47}$ Phosphatase and tensin homolog deleted from chromosome 10

${ }^{48}$ PKB: protein kinase $\mathrm{B}$

${ }^{49}$ Forkhead box O3a

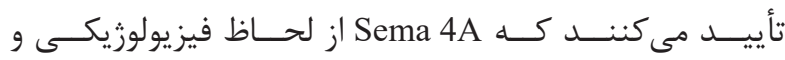

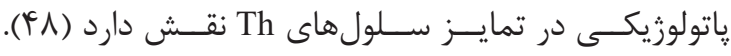

Treg و پوايدارى سلول Sema 4A

از طريــ Sema 4A

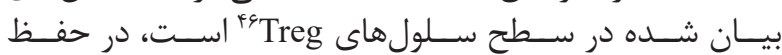

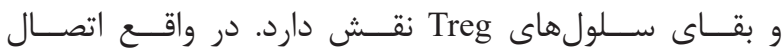

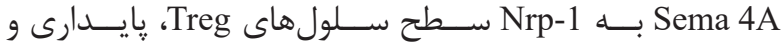

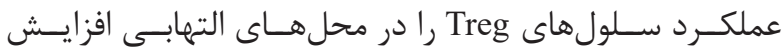

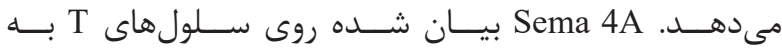

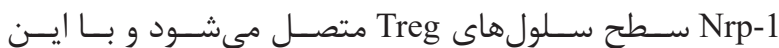

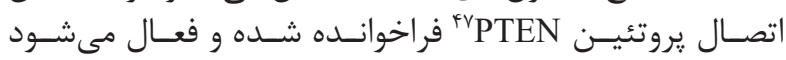

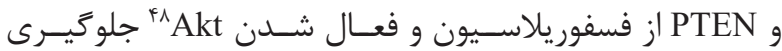

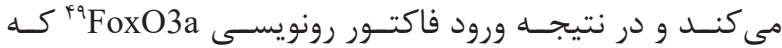

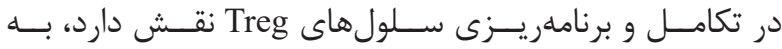

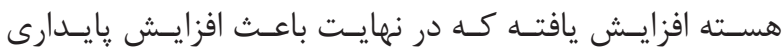

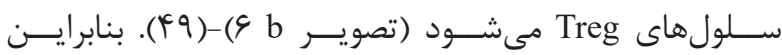

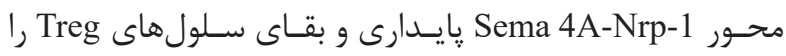

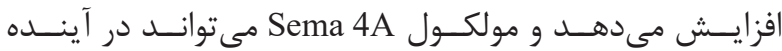

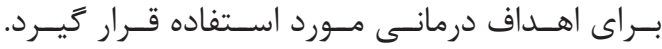

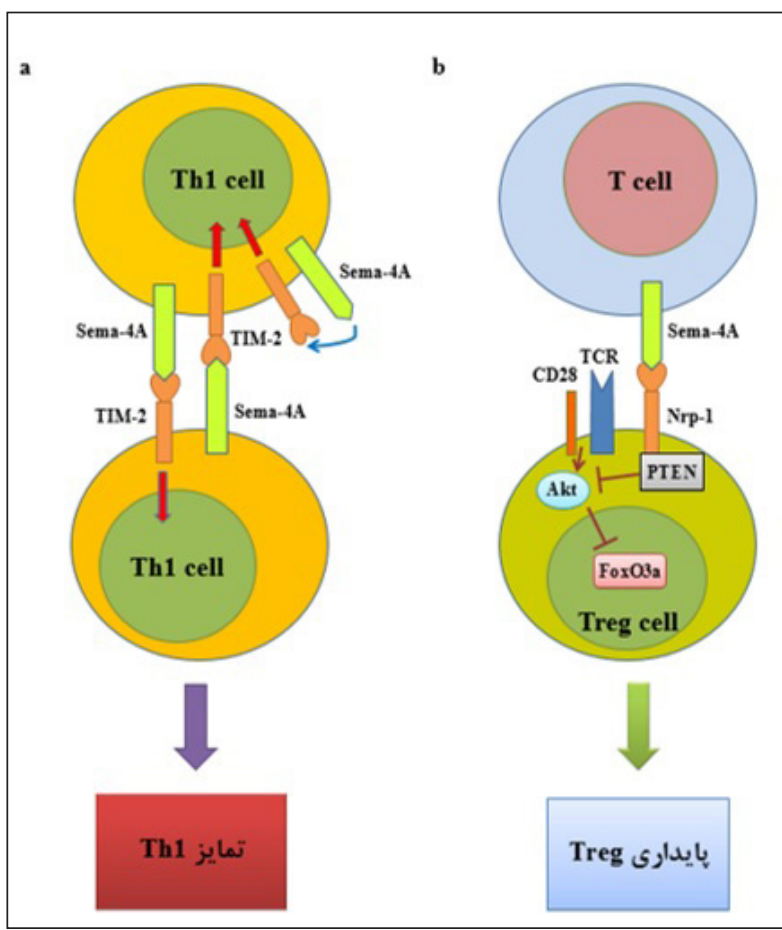

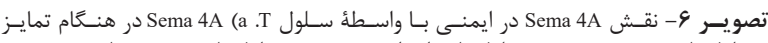

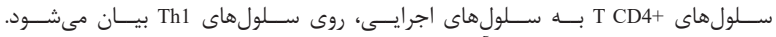

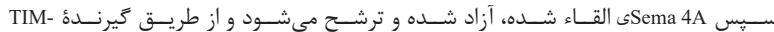

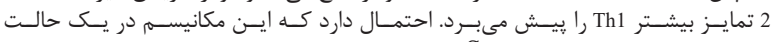

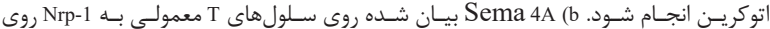

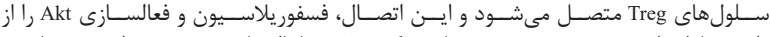

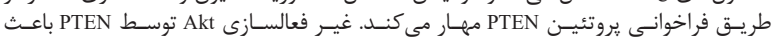

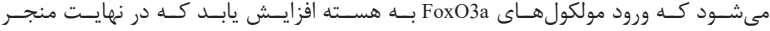

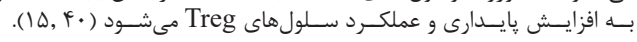

${ }^{50}$ Myelin oligodendrocyte glycoprotein

${ }^{51}$ Mixed-lymphocyte reaction

${ }^{52}$ Concanavalin A 


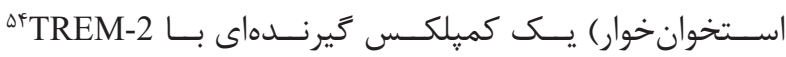

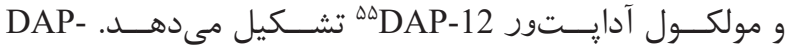

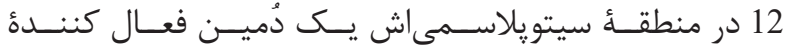

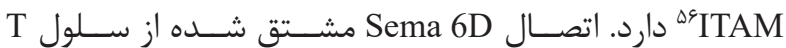

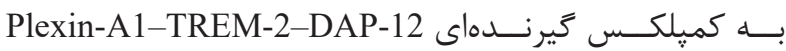

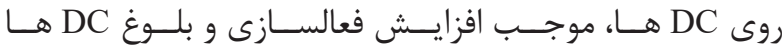

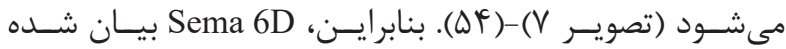

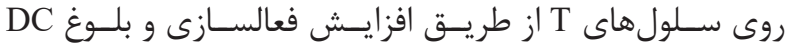

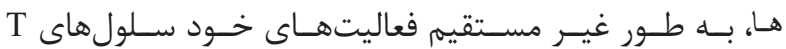

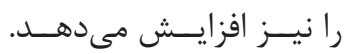

\section{Sema 7A}

Sema 7A

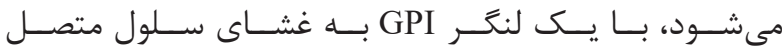

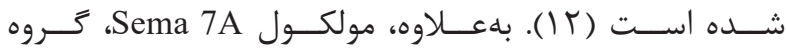

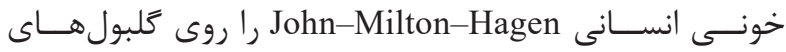

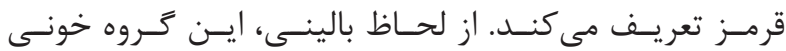

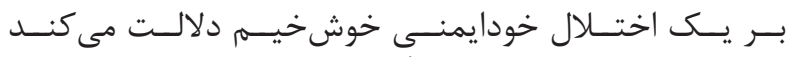

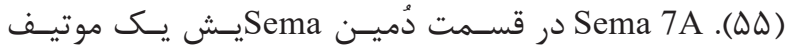

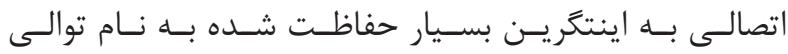

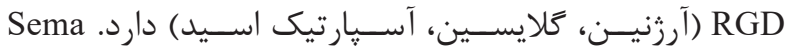

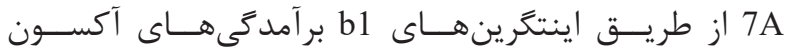

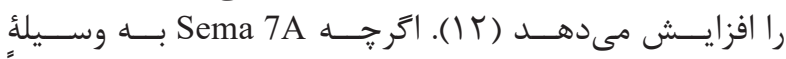

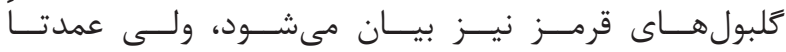

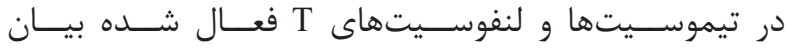

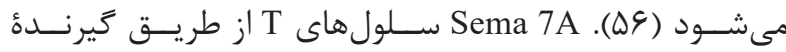

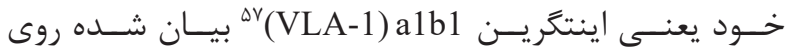

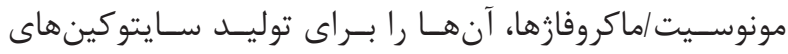

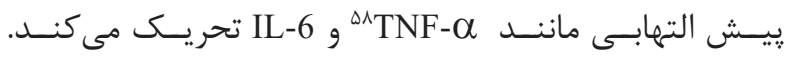

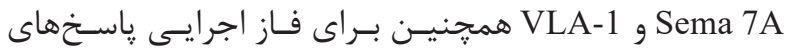

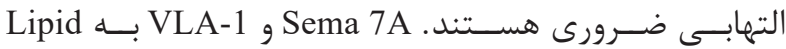
هaft

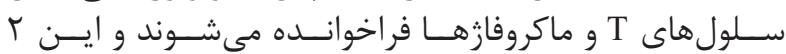

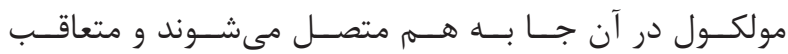

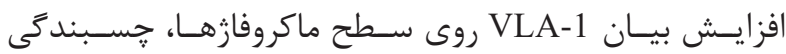

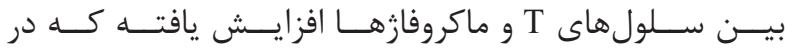

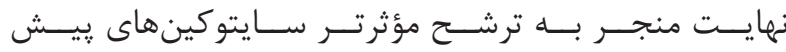

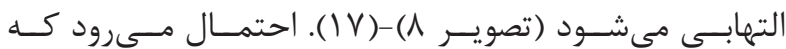
Sema 7A

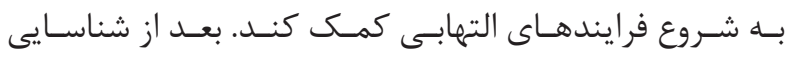

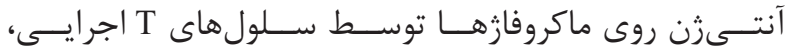

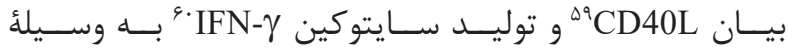

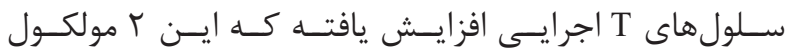

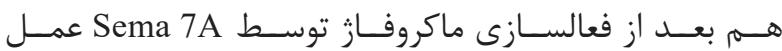

${ }^{53}$ Thy-1+ dendritic epidermal cells

${ }^{54}$ Triggering receptor expressed on myeloid cells 2

${ }^{55}$ DNAX-activating protein 12

${ }^{56}$ Immunoreceptor tyrosine-based activation motif
يلكسـين -B2 يـا Sema 4D، فعالسـازى سـلول Tgd را مهــار

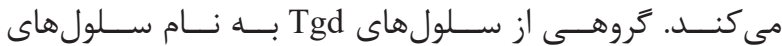

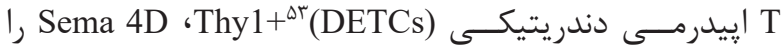

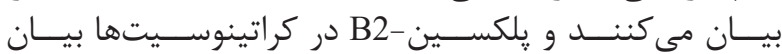

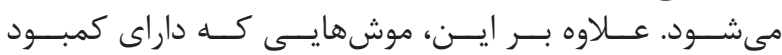
Sema 4D

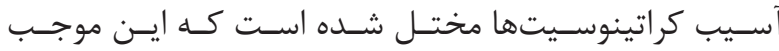

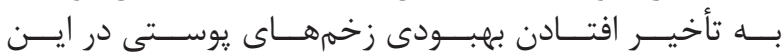

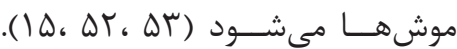

\section{DC-T و ارتباطات سلول Sema 6D}

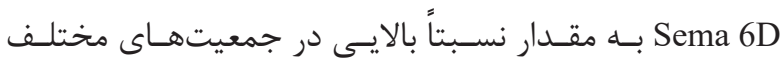

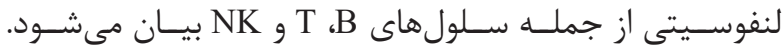

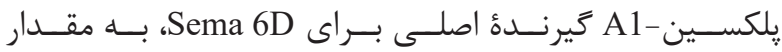

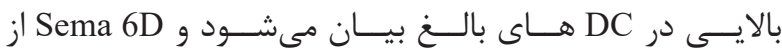

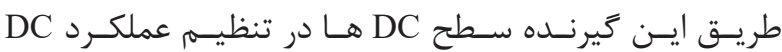

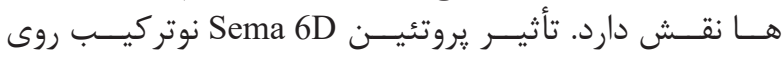

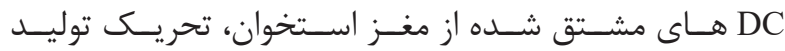

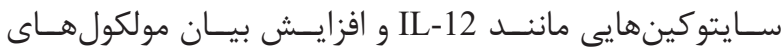

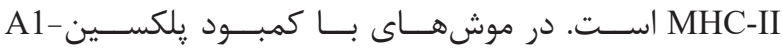

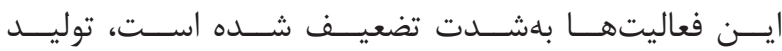

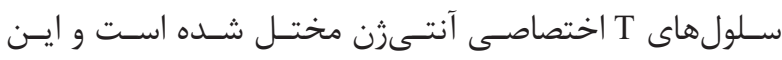

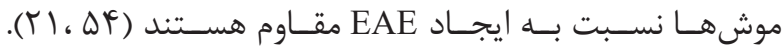

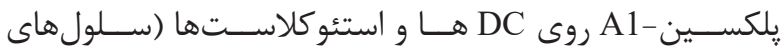

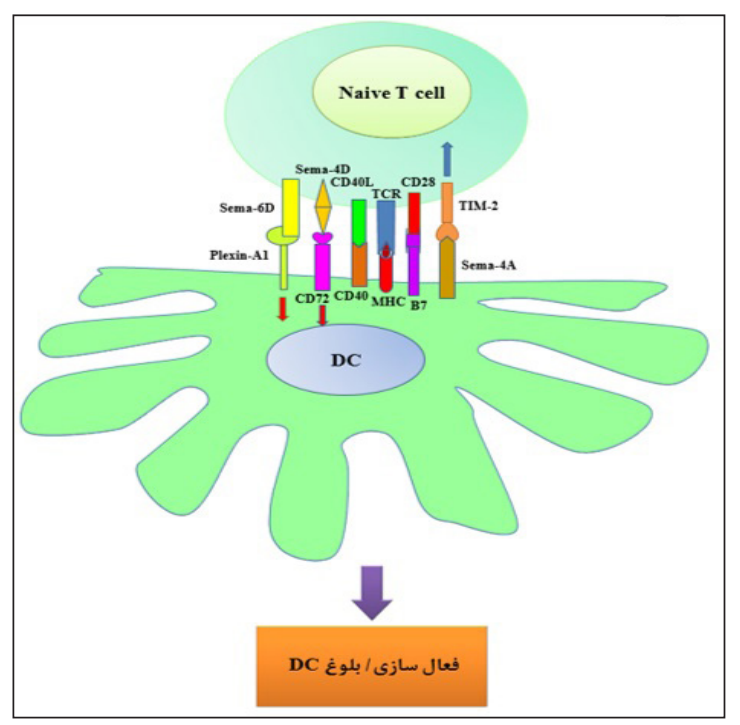

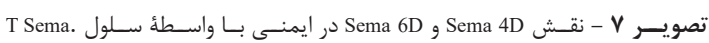

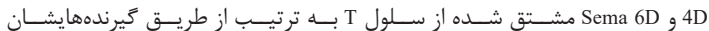

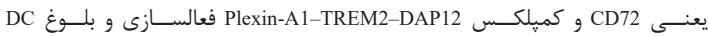

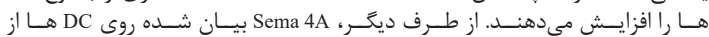

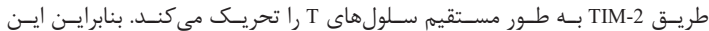

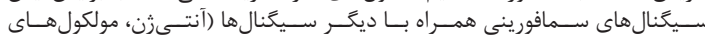

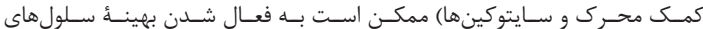

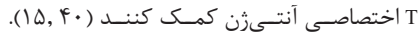

\footnotetext{
${ }^{57}$ Very late antigen- 1

${ }^{58}$ Tumor necrosis factor alpha

${ }^{59} \mathrm{CD} 40$ ligand

${ }^{60}$ Interferon-g
} 


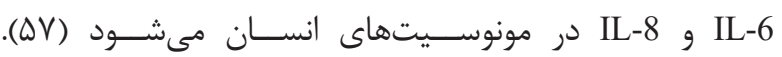

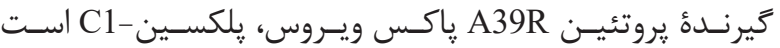

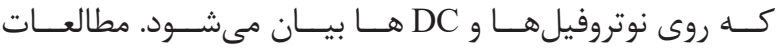

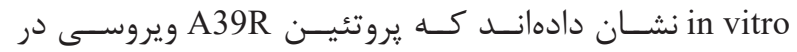

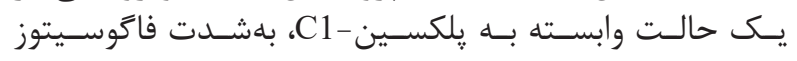

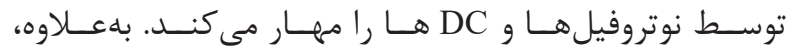

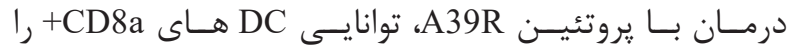

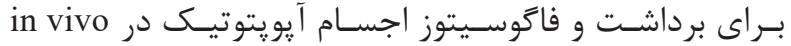

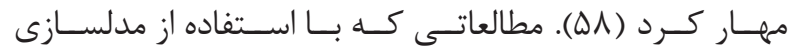

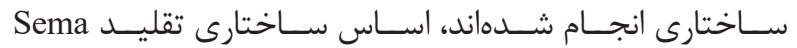

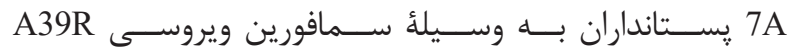

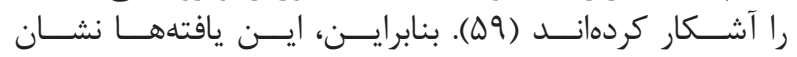

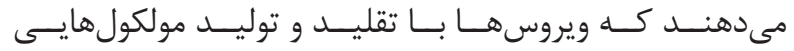

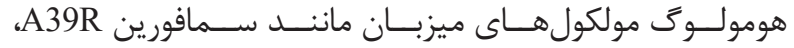

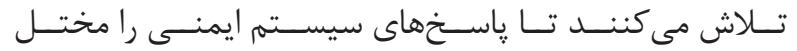

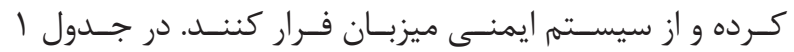

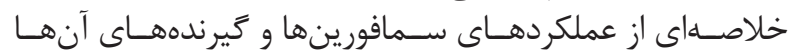

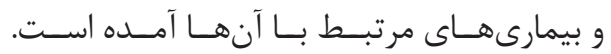
نقش سمافورين ها در بيمارى مالتييل اسكلروز

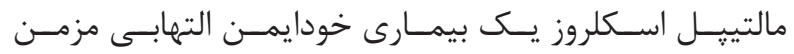

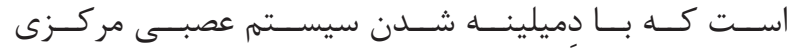

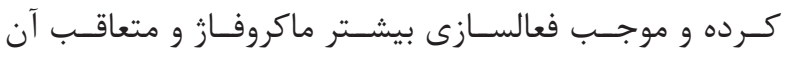

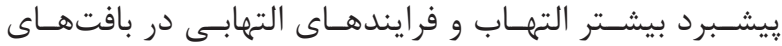

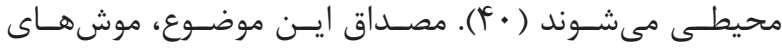

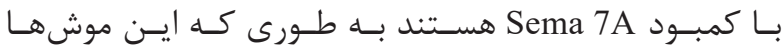

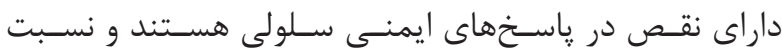

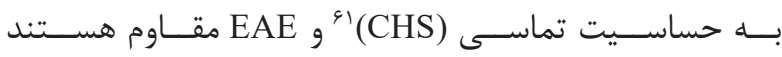

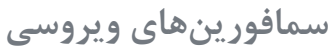

مشـخص شـده كـه يروتئين هـاى شــبه سـمافورين در تهندين DNA

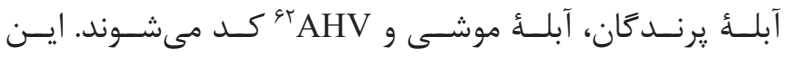

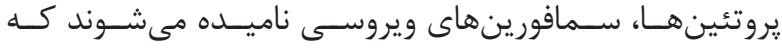

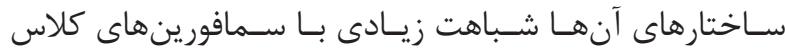

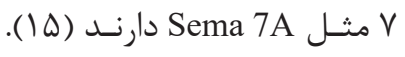

سمافورين A39R

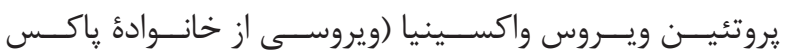

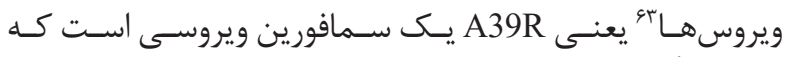

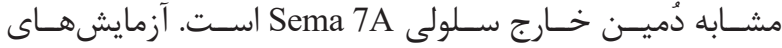

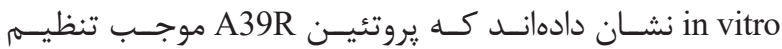

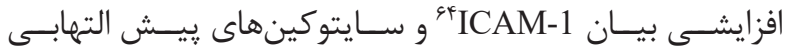

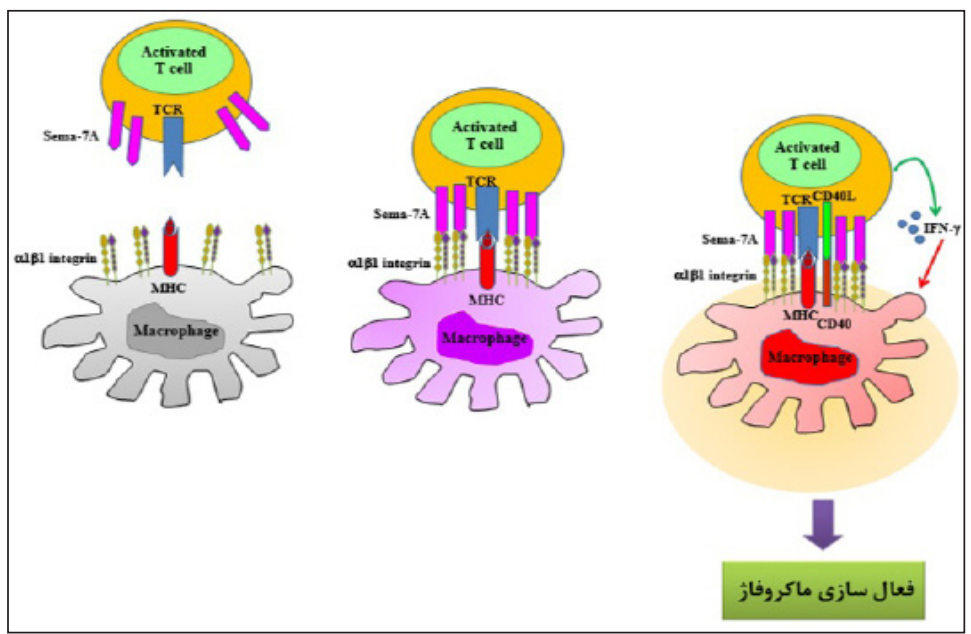

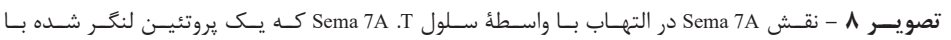

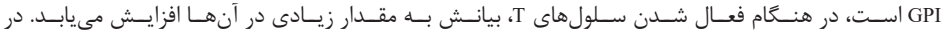

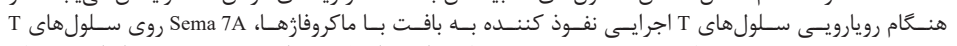

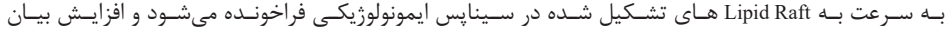

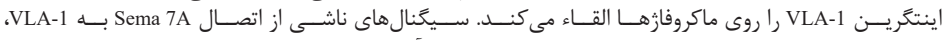

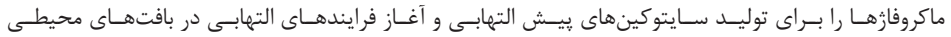

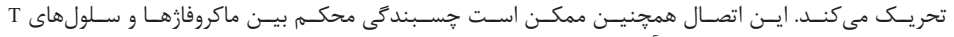

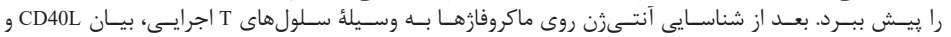

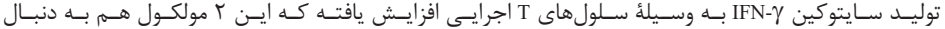

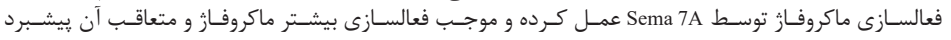

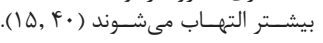

${ }^{61}$ Contact hypersensitivity

${ }^{62}$ Alcelaphine herpes virus type 1 virus
${ }^{63}$ Poxvirus

${ }^{64}$ Intercellular adhesion molecule-1: CD54 
جدول ا- عملكردهاى سمافورينها و كيرندهايشان در سيستم ايمنى (9V-•(9).

\begin{tabular}{|c|c|c|c|c|}
\hline بيعارى مايط & عملكردعا & ليكاتسها|كيرتدهما & بيان ثر سلولهماي سيستم الويروسا & سمافورينها آكيرندمائ \\
\hline 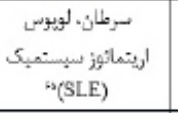 & 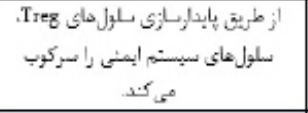 & 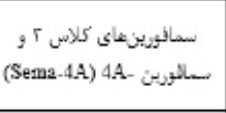 & 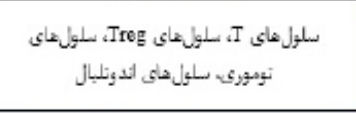 & توروييلين-1 (Nrp-1) \\
\hline 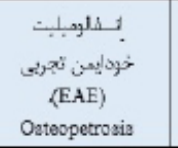 & 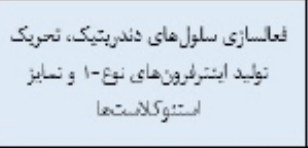 & 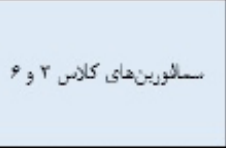 & 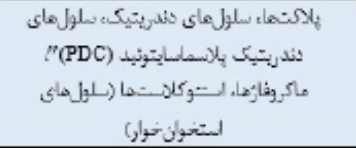 & Plexin-Al \\
\hline .EAE & 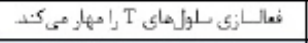 & 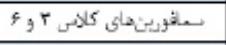 & 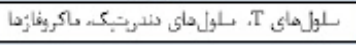 & Plexin-A4 \\
\hline 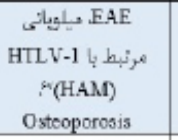 & 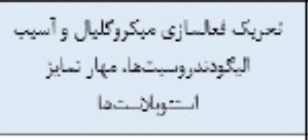 & 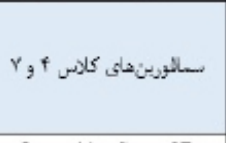 & 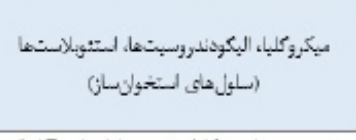 & Plexin-BI \\
\hline نشخص نبست & 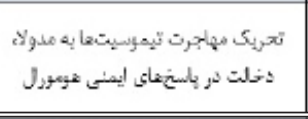 & 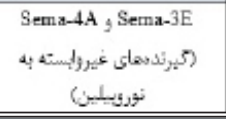 & 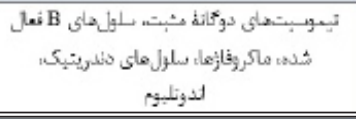 & Plexim-DI \\
\hline مشيخص نيست & 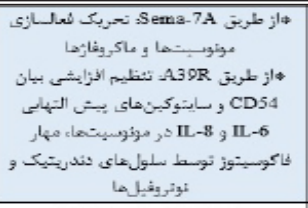 & A39R $S=m x-7 A$ & سلول هاي دندريتبك، نوتروليلها & Plexin Cl \\
\hline EAE & 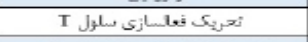 & Sema-4A & 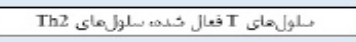 & TIM-2 \\
\hline SLE & 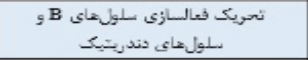 & Sema-4D & سلول عاى B سلول عاي حندريتيك & $\operatorname{CD} 72$ \\
\hline 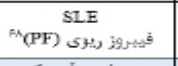 & 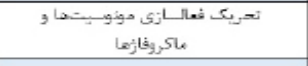 & Sema.7A & 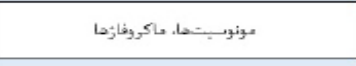 & (al $\beta 1$ integrin) VLA-1 \\
\hline 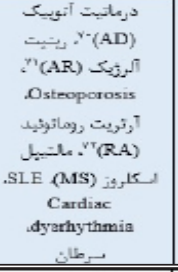 & 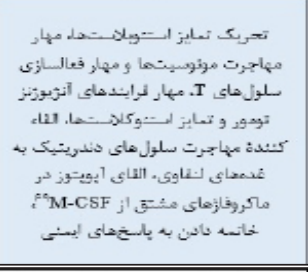 & 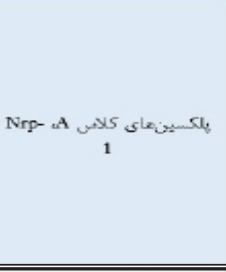 & 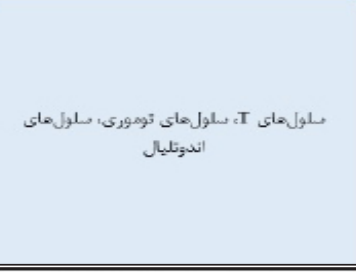 & Sema-3A \\
\hline شخصى نبـت & 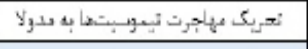 & Plexin-D1 & 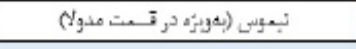 & Sema-3E \\
\hline $\begin{array}{l}\text { AD MS L̨ EAE } \\
\text { Pigmentary } \\
\text { retinopethy }\end{array}$ & 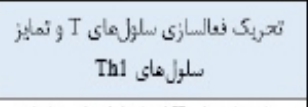 & 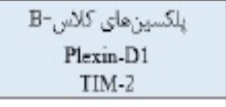 & 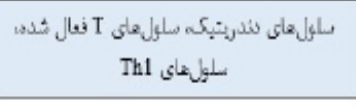 & Sema-4A \\
\hline ثخصى نبــت & 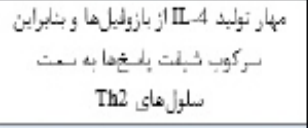 & 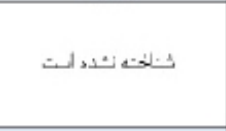 & 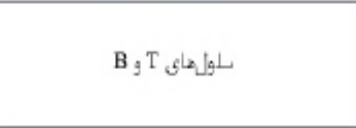 & Sema-AB \\
\hline $\begin{array}{l}\text { Allergic Ainway } \\
\text { Inflammation }\end{array}$ & 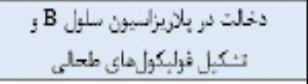 & Plexin-B2 ill $=1$ & 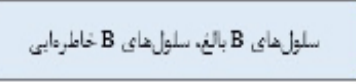 & Sema-4C \\
\hline $\begin{array}{l}\text { HAM EAE } \\
\text { Osteopetrosis }\end{array}$ & 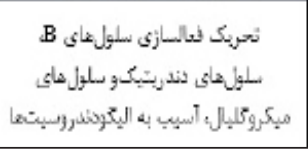 & $\begin{array}{l}\text { Plexin-B1 } \\
\text { CD } 72\end{array}$ & 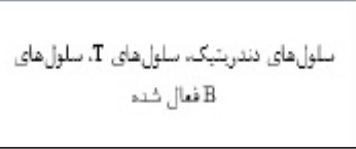 & Sema-4D \\
\hline 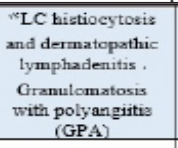 & تحريكا تشكيل كرلتولوم & $\begin{array}{l}\text { "VEGER2-PlexinA1- } \\
\text { Off track }\end{array}$ & 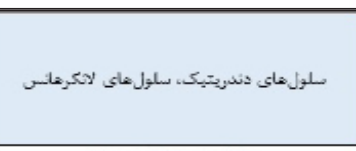 & $\operatorname{Sem} \mathbf{x}-6 \mathbf{A}$ \\
\hline Osteopetrosis & 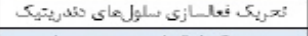 & Plexin-A1 & 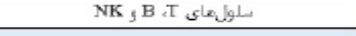 & $\operatorname{Sema-\sigma D}$ \\
\hline 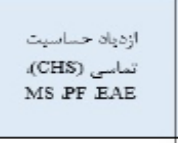 & 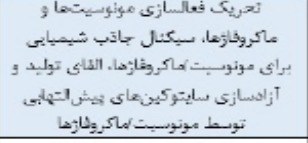 & $\begin{array}{l}\text { Plesin-C1 } \\
\text { VLA-1 }\end{array}$ & 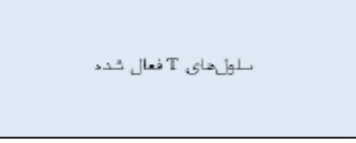 & Sema-7A \\
\hline 草 & 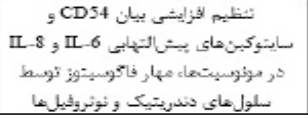 & Plexin-C1 & 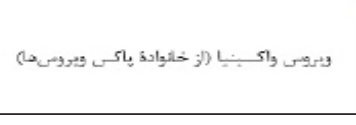 & A39R سعاقورين ويروسى A \\
\hline
\end{tabular}

${ }^{65}$ SLE: Systemic lupus erythematosus

${ }^{66}$ PDC: Plasmacytoid dendritic cell

${ }^{67}$ HAM: HTLV1-associated myelopathy

${ }^{68} \mathrm{PF}$ : Pulmonary fibrosis

${ }^{69} \mathrm{M}$-CSF: Macrophage-colony stimulating factor
${ }^{70} \mathrm{AD}$ : Atopic dermatitis

${ }^{71}$ AR: Allergic rhinitis

${ }^{72} \mathrm{RA}$ : Rheumatoid arthritis

${ }^{73}$ VEGFR2: Vascular endothelial growth factor receptor-2

${ }^{74}$ LC: Langerhans cell 


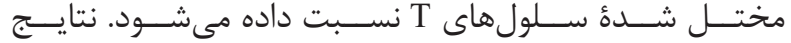

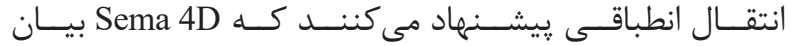

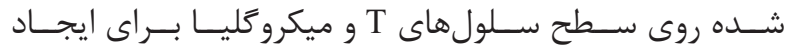

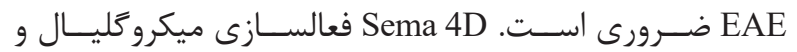

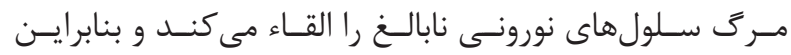

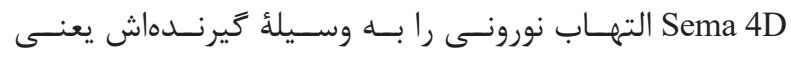

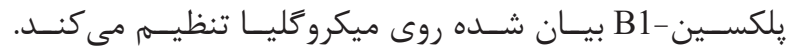

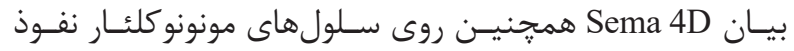

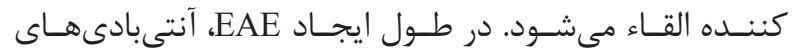

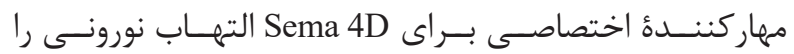

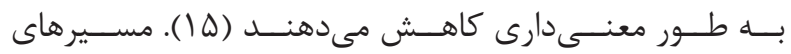

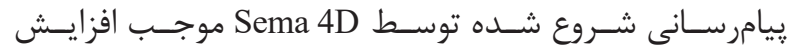

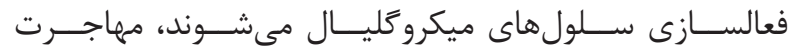

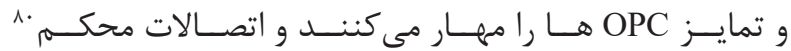

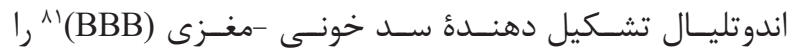

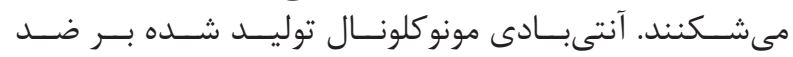

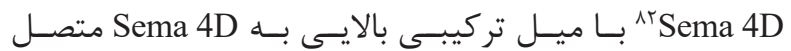

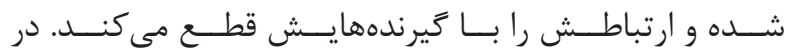
anti-SEMA4D in vitro

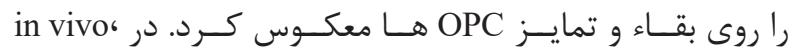

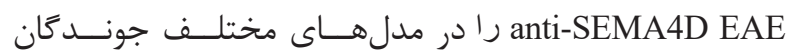

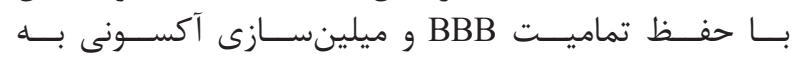

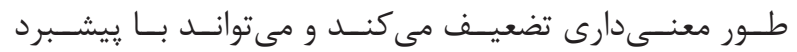

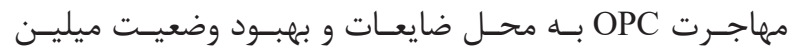

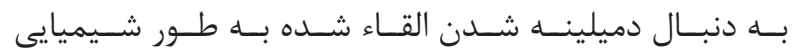

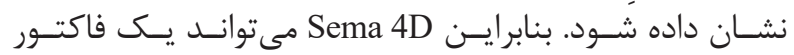

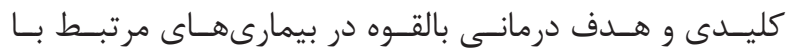

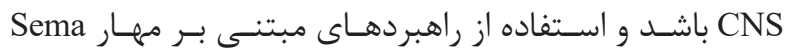

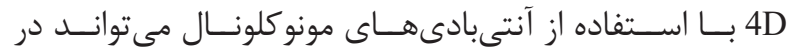

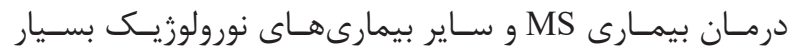

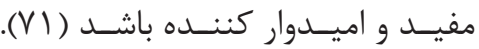

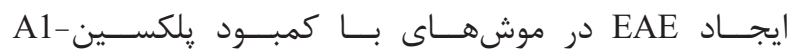

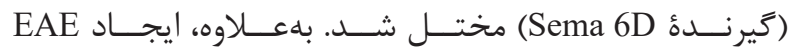

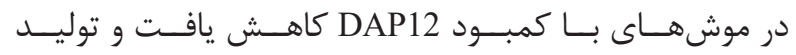

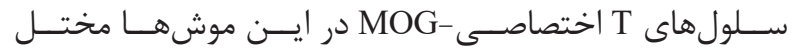

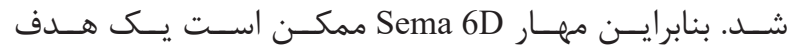

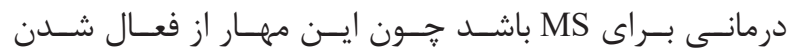

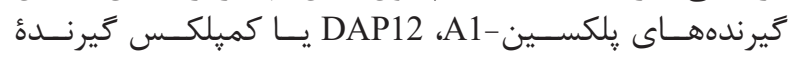

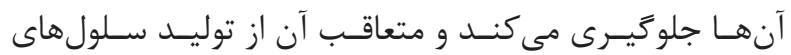

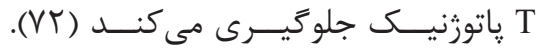

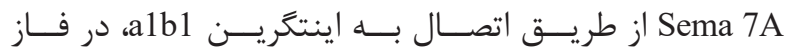

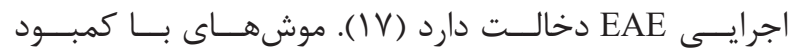

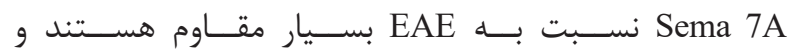

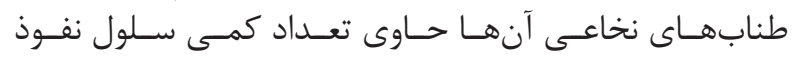

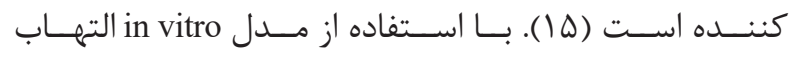

${ }^{75}$ Central nervous system

${ }^{76}$ Oligodendrocyte precursor cell

${ }^{77}$ Myelination

${ }^{78}$ Sema4A-deficient: Sema 4A-KO

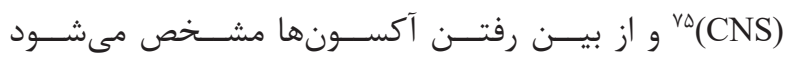

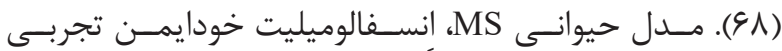

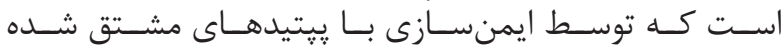

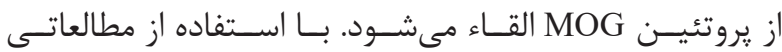

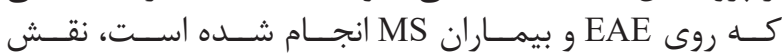

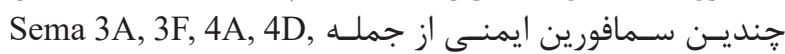

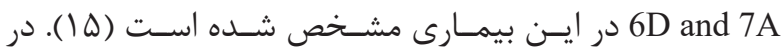

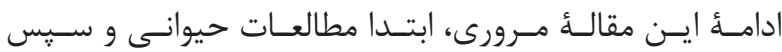

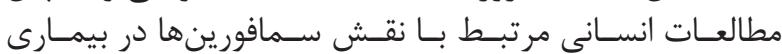

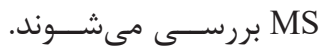

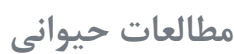
ناتوانسى ســلول وِيشســاز اليخودندروسـيت (OPC)

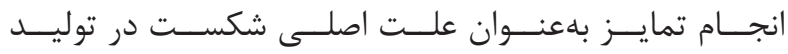

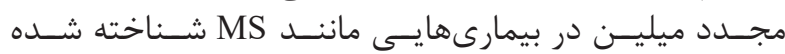

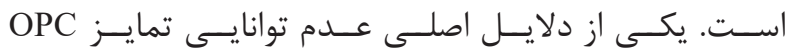

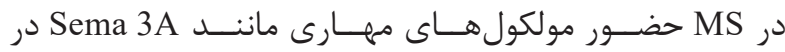

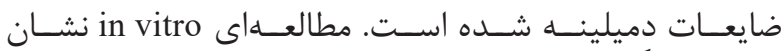

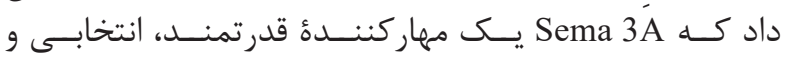

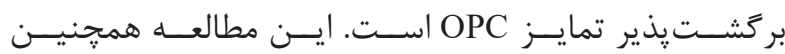

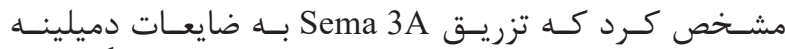

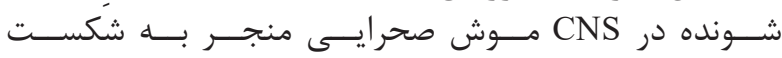

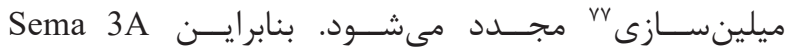

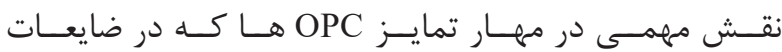

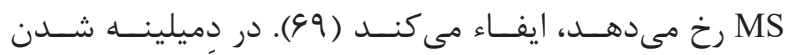

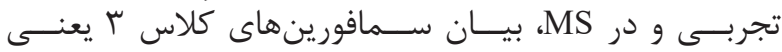

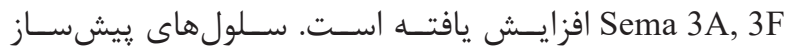

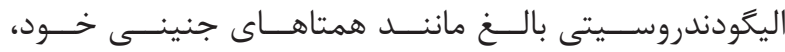

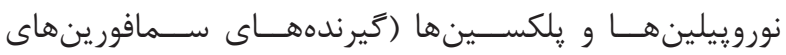

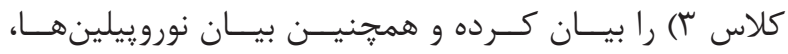

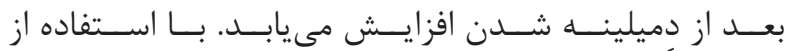

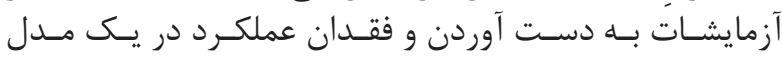

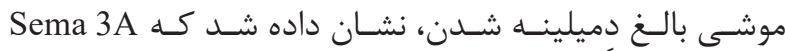

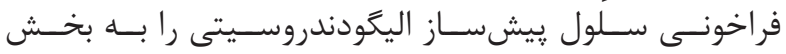

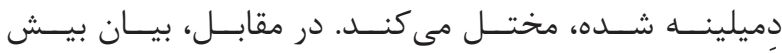

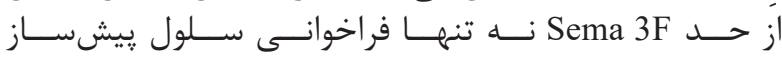

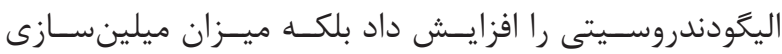

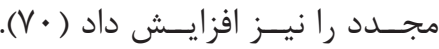
موشهــاى بــا كمبـود

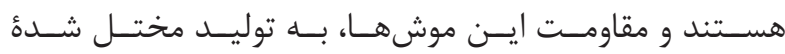

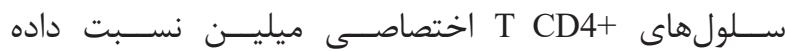

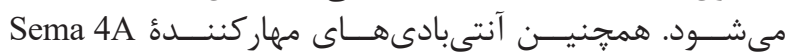

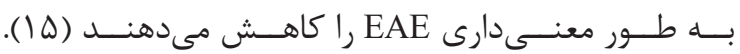

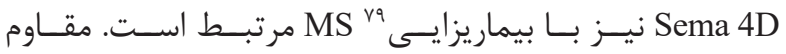

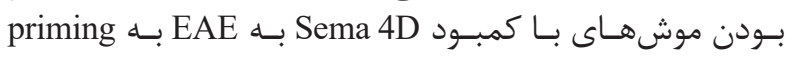

${ }^{79}$ Pathogenesis

${ }^{80}$ Tight junctions

${ }^{81}$ Blood brain barrier

${ }^{82}$ Anti-SEMA4D 
در ضايعـات بيمـاران MS Immunostaining

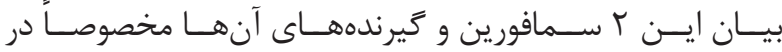

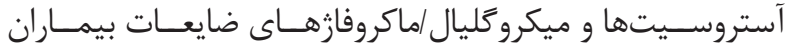

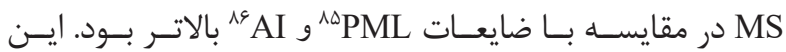

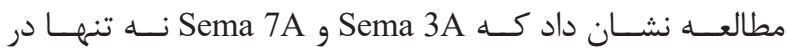

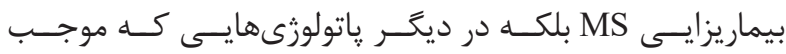

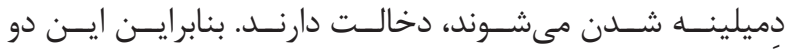

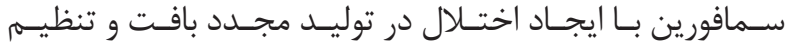

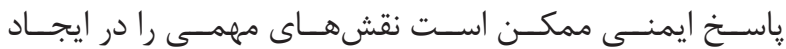

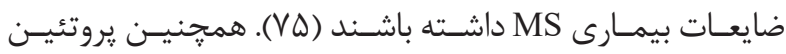

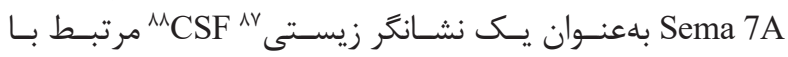

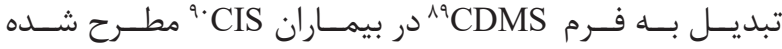

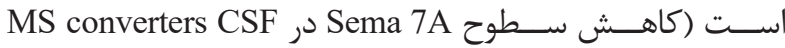

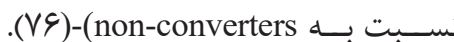

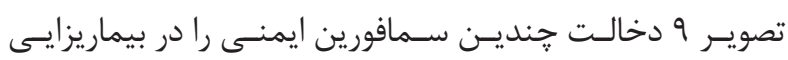

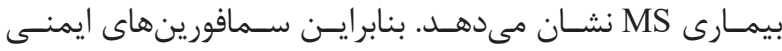

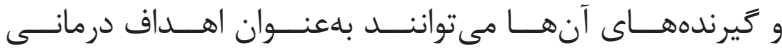

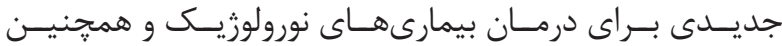

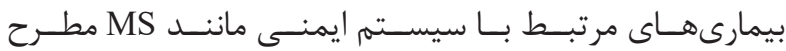

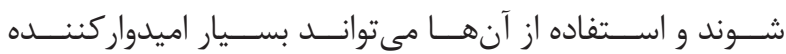

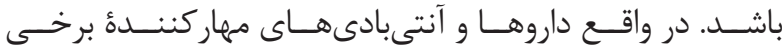

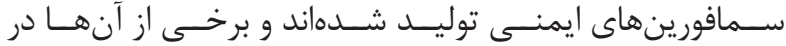

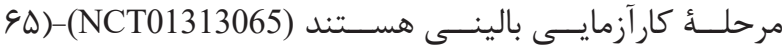

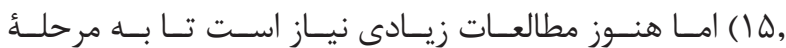

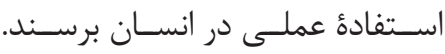

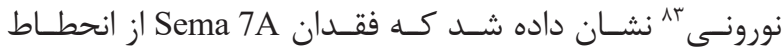

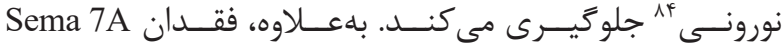

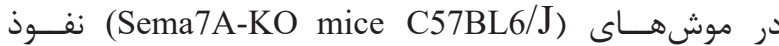

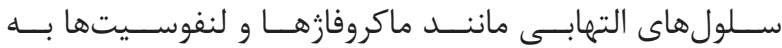

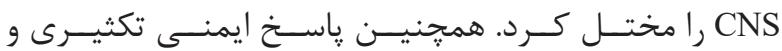

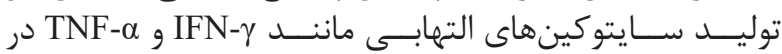

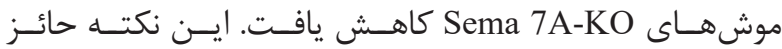

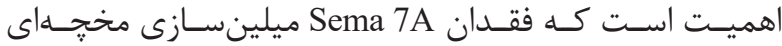

$$
\begin{aligned}
& \text { را تغييــر نــداد (VT). } \\
& \text { مطالعات انسانى }
\end{aligned}
$$

ســـوح ســرمى Sema 4A در بيمـــاران MS افزايــش يافتـــهـ

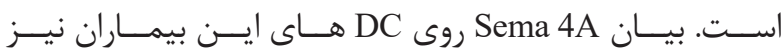

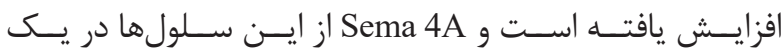

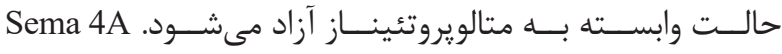

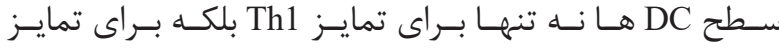

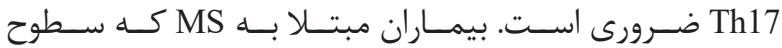

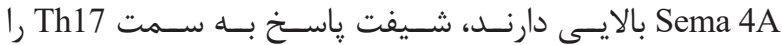

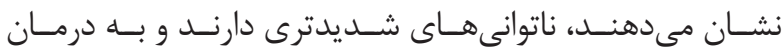

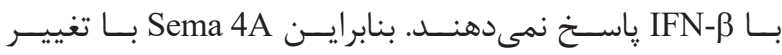

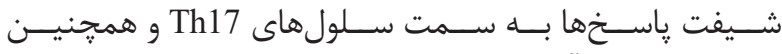

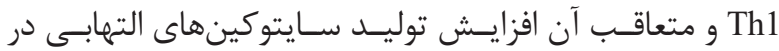

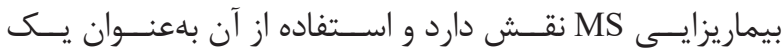

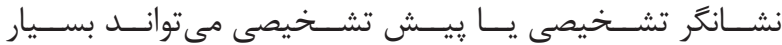

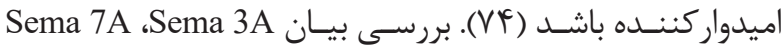

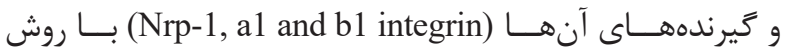

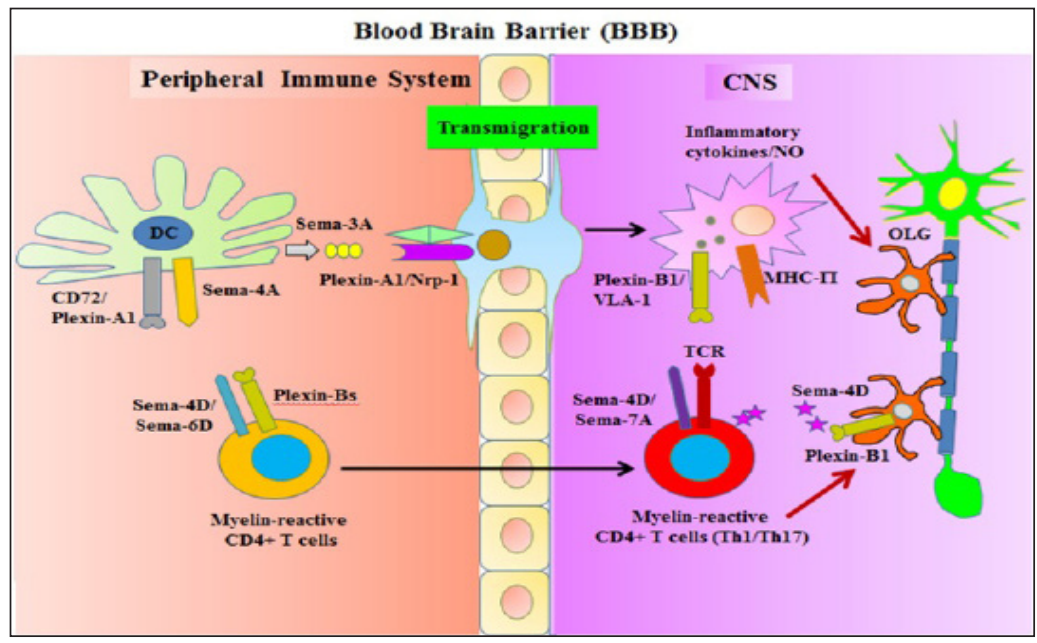

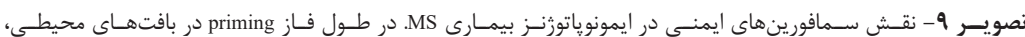

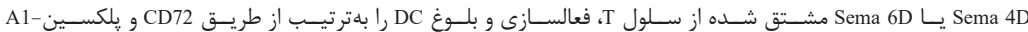

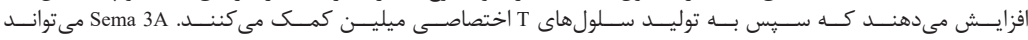

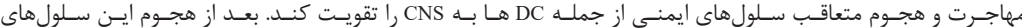

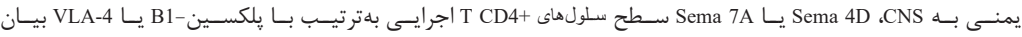

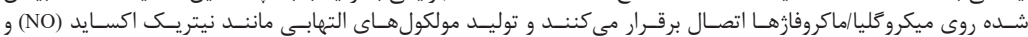

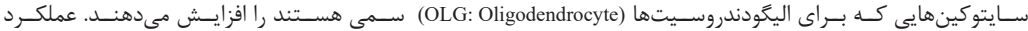

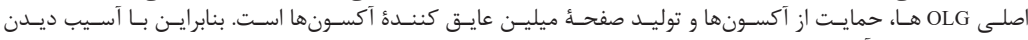

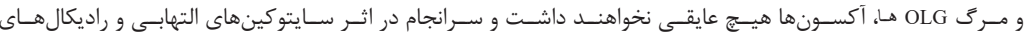

${ }^{83}$ Neuroinflammation

${ }^{84}$ Neurodegeneration

${ }^{85}$ Progressive multifocal leucoencephalopathy

${ }^{86}$ Acute cerebral infarct

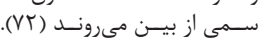

\footnotetext{
${ }^{87}$ Bio marker

${ }^{88}$ Cerebrospinal fluid

${ }^{89}$ Clinically definite MS

${ }^{90}$ Clinically isolated syndromes
} 


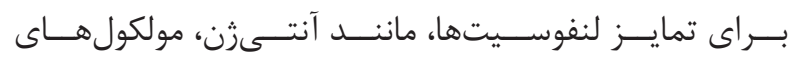

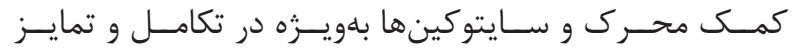

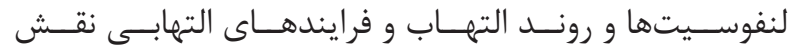

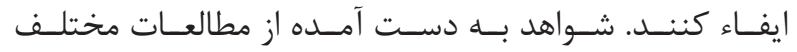

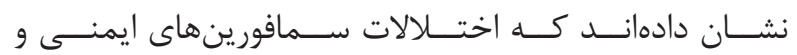

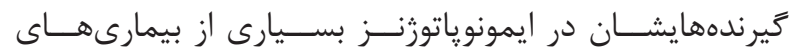

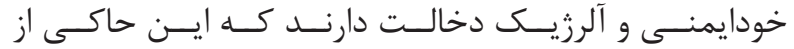

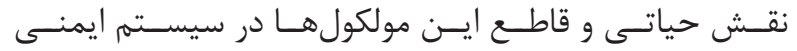

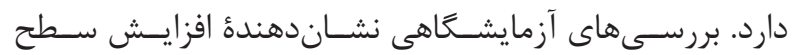

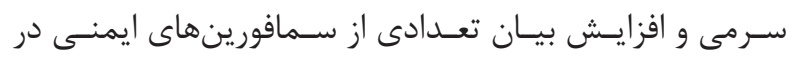

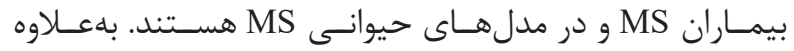

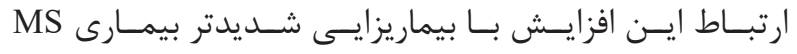

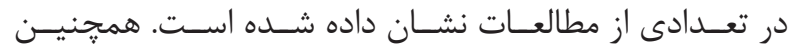

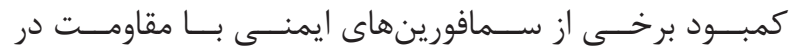

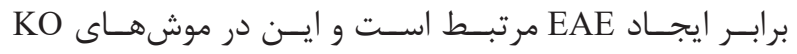

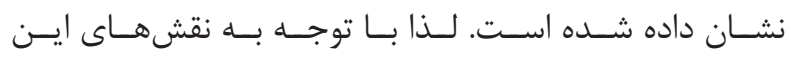

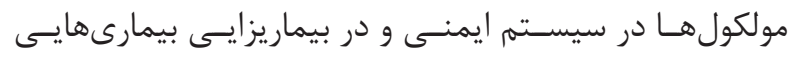

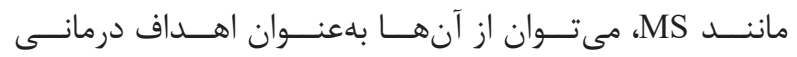

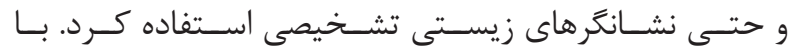

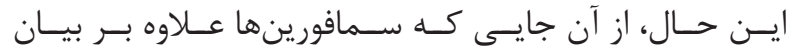

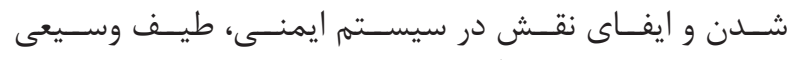

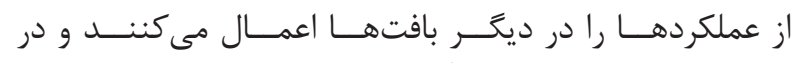

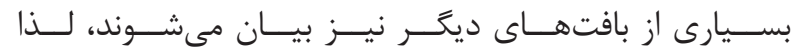

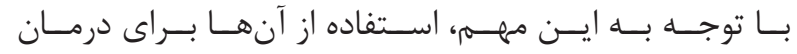

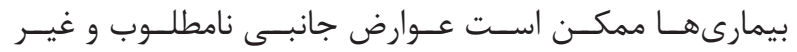

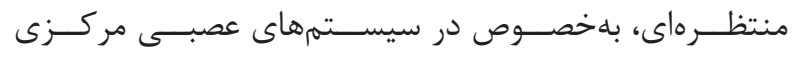

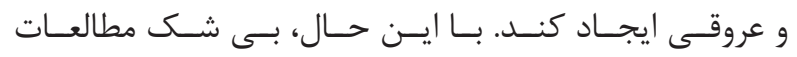

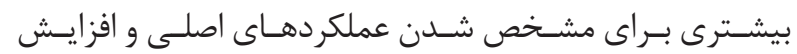

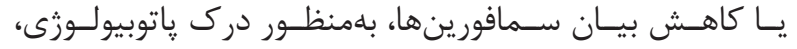

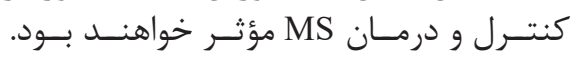

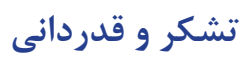

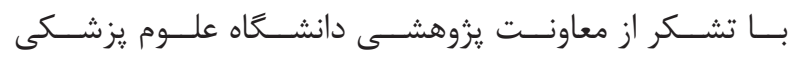

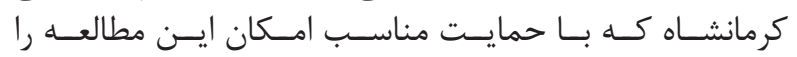

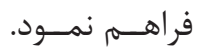

اهميـــت ســمافورينها در درمـــان بيمــارى مالتييــل

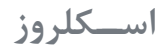

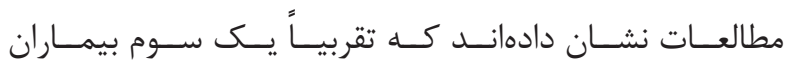

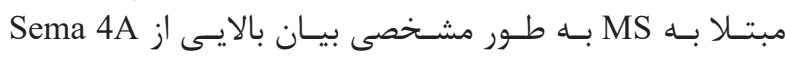

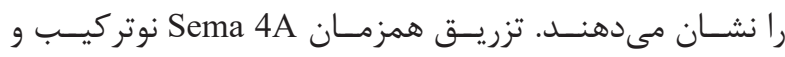

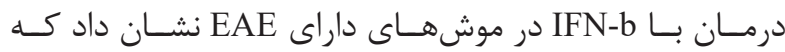

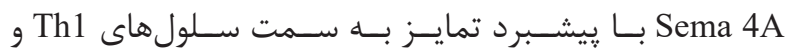

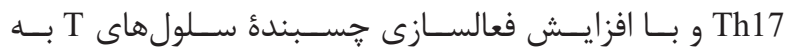

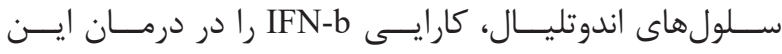

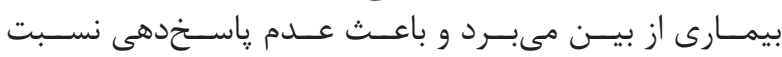

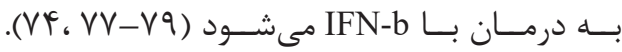

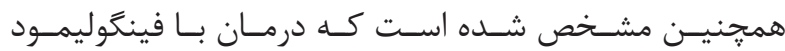

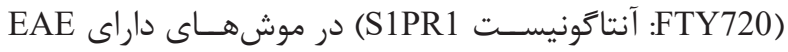

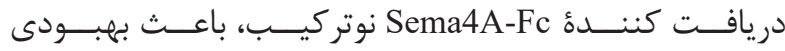

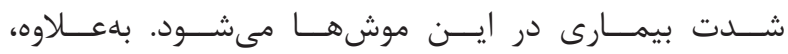

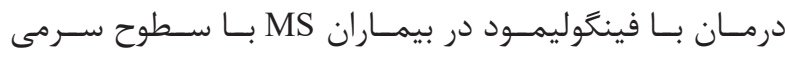

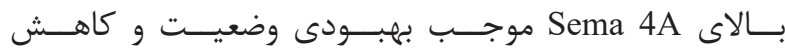

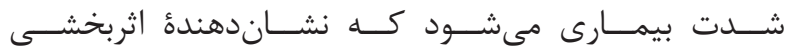

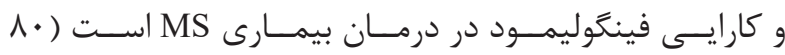

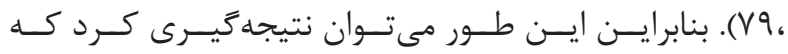

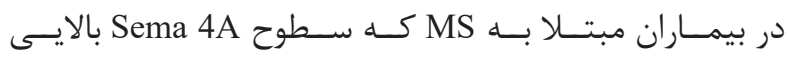

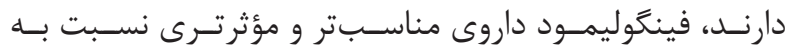

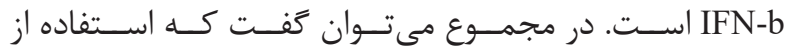

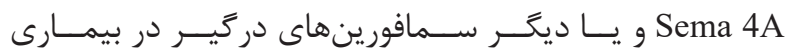

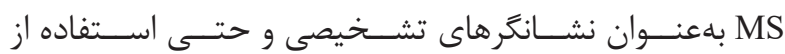

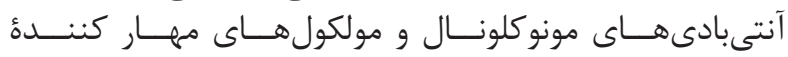

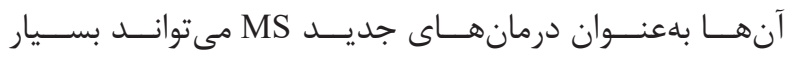

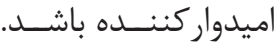
نتيجه

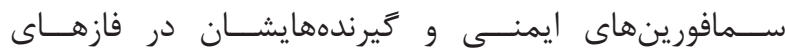

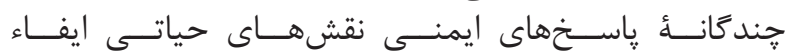

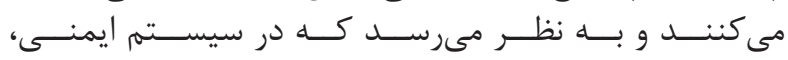

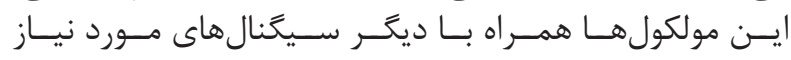


1. Kolodkin AL, Matthes DJ, Goodman CS. The semaphorin genes encode a family of transmembrane and secreted growth cone guidance molecules. Cell. 1993; 75(7): 1389-99.

2. Pasterkamp RJ, Kolodkin AL. Semaphorin junction: making tracks toward neural connectivity. Curr Opin Neurobiol. 2003; 13(1): 79-89.

3. Negishi M, Oinuma I. Semaphorins. Springer. 2015; p. 1-17.

4. Goodman C, Kolodkin A, Luo Y, Püschel A RJ. Unified nomenclature for the semaphorins/collapsins. semaphorin nomenclature committee. Cell. 1999; 97(5): 551-2.

5. Kumanogoh A, Kikutani H. Immune semaphorins: a new area of semaphorin research. J Cell Sci. 2003; 116(17): 3463-70.

6. Potiron V, Nasarre P, Roche J, Healy C, Boumsell L. Semaphorin signaling in the immune system. Semaphorins: Receptor and Intracellular Signaling Mechanisms. Springer; 2007. p. 132-44.

7. Takahashi T, Fournier A, Nakamura F, Wang L-H, Murakami Y, Kalb RG, et al. Plexin-neuropilin-1 complexes form functional semaphorin-3A receptors. Cell. 1999; 99(1)59-69.

8. Tamagnone L, Artigiani S, Chen H, He Z, Ming G, Song $\mathrm{H}$, et al. Plexins are a large family of receptors for transmembrane, secreted, and GPI-anchored semaphorins in vertebrates. Cell. 1999; 99(1): 71-80.

9. Winberg ML, Noordermeer JN, Tamagnone L, Comoglio PM, Spriggs MK, Tessier-Lavigne M, et al. Plexin A is a neuronal semaphorin receptor that controls axon guidance. Cell. 1998; 95(7): 903-16.

10. Kang S, Kumanogoh A. Semaphorins in bone development, homeostasis, and disease. Seminars in Cell and Developmental Biology. Elsevier; 2013. p. 163-71.

11. Abbas AK, Lichtman AH, Pillai S. Cellular and molecular immunology. $9^{\text {th }}$ ed. Elsevier. 2017; p. 25-49.

12. Pasterkamp RJ, Peschon JJ, Spriggs MK, Kolodkin AL. Semaphorin 7A promotes axon outgrowth through integrins and MAPKs. Nature. 2003; 424(6947): 398405 .

13. Kumanogoh A, Watanabe C, Lee I, Wang X, Shi W, Araki H, et al. Identification of CD72 as a lymphocyte receptor for the class IV semaphorin CD100: a novel
منابع

mechanism for regulating $\mathrm{B}$ cell signaling. Immunity. 2000; 13(5): 621-31.

14. Kumanogoh A, Marukawa S, Suzuki K, Takegahara N, Watanabe C, Ch'ng E, et al. Class IV semaphorin Sema4A enhances T-cell activation and interacts with Tim-2. Nature. 2002; 419(6907): 629-33.

15. Nojima S, Kumanogoh A. Semaphorins in the immune system. Semaphorins. Springer; 2015. p. 137-57.

16. Zhou Y, Gunput R-AF, Pasterkamp RJ. Semaphorin signaling: progress made and promises ahead. Trends Biochem Sci. 2008; 33(4): 161-70.

17. Suzuki K, Okuno T, Yamamoto M, Pasterkamp RJ, Takegahara N, Takamatsu H, et al. Semaphorin 7A initiates T-cell-mediated inflammatory responses through alpha1beta1 integrin. Nature. 2007; 446(7136): 680-4.

18. Gu C, Yoshida Y, Livet J, Reimert DV, Mann F, Merte J, et al. Semaphorin 3E and plexin-D1 control vascular pattern independently of neuropilins. Science. 2005; 307(5707): 265-8.

19. Takamatsu H, Kumanogoh A. Diverse roles for semaphorin- plexin signaling in the immune system. Trends Immunol. 2012; 33(3): 127-35.

20. Roney K, Holl E, Ting J. Immune plexins and semaphorins: old proteins, new immune functions. Protein Cell. 2013; 4(1): 17-26.

21. Wong AW, Brickey WJ, Taxman DJ, van Deventer HW, Reed W, Gao JX, et al. CIITA-regulated plexin-A1 affects T-cell-dendritic cell interactions. Nat Immunol. 2003; 4(9): 891-8.

22. Takamatsu H, Takegahara N, Nakagawa Y, Tomura M, Taniguchi M, Friedel RH, et al. Semaphorins guide the entry of dendritic cells into the lymphatics by activating myosin II. Nat Immunol. 2010; 11(7): 594-600.

23. Gu C, Giraudo E. The role of semaphorins and their receptors in vascular development and cancer. Exp Cell Res. 2013; 319(9): 1306-16.

24. Alvarez D, Vollmann EH, von Andrian UH. Mechanisms and consequences of dendritic cell migration. Immunity. 2008; 29(3): 325-42.

25. Takamatsu H, Okuno T, Kumanogoh A, Takamatsu H. Regulation of immune cell responses by semaphorins and their receptors. Arthritis Res Ther. 2010; 7(2): 1-54.

26. Lepelletier Y, Moura IC, Hadj Slimane R, Renand A, 


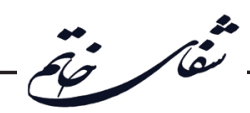

Fiorentino S, Baude C, et al. Immunosuppressive role of semaphorin $3 \mathrm{~A}$ on $\mathrm{T}$ cell proliferation is mediated by inhibition of actin cytoskeleton reorganization. Eur $\mathrm{J}$ Immunol. 2006; 36(7): 1782-93.

27. Moretti S, Procopio A, Lazzarini R, Rippo MR, Tes ta R, Marra M, et al. Semaphorin 3A signaling controls Fas (CD95)-mediated apoptosis by promoting Fas translocation into lipid rafts. Blood. 2008; 111(4): 2290-9.

28. Yamamoto M, Suzuki K, Okuno T, Ogata T, Takegahara N, Takamatsu H, et al. Plexin-A4 negatively regulates $\mathrm{T}$ lymphocyte responses. Int Immunol. 2008; 20(3): 413-20.

29. Mizui M, Kumanogoh A, Kikutani H. Immune semaphorins: novel features of neural guidance molecules. J Clin Immunol. 2009; 29(1): 1-11.

30. Kumanogoh A, Shikina T, Suzuki K, Uematsu S, Yukawa K, Kashiwamura S-I, et al. Nonredundant roles of Sema4A in the immune system: defective $\mathrm{T}$ cell priming and $\mathrm{Th} 1 / \mathrm{Th} 2$ regulation in Sema4A-deficient mice. Immunity. 2005; 22(3): 305-16.

31. Nakagawa Y, Takamatsu H, Okuno T, Kang S, Nojima S, Kimura T, et al. Identification of semaphorin $4 \mathrm{~B}$ as a negative regulator of basophil-mediated immune responses. J Immunol. 2011; 186(5): 2881-8.

32. Karasuyama H, Mukai K, Obata K, Tsujimura Y, Wada T. Nonredundant roles of basophils in immunity. Annu Rev Immunol. 2011; 29: 45-69.

33. Kataoka TR, Kumanogoh A, Bandara G, Metcalfe DD, Gilfillan AM. CD72 negatively regulates KITmediated responses in human mast cells. J Immunol. 2010; 184(5): 2468-75.

34. Delaire S, Elhabazi A, Bensussan A, Boumsell L. CD100 is a leukocyte semaphorin. Cell Mol Life Sci. 1998; 54(11): 1265-76.

35. Bougeret C, Mansur I-G, Dastot H, Schmid M, Mahouy G, Bensussan A, et al. Increased surface expression of a newly identified 150-kDa dimer early after human T lymphocyte activation. J Immunol. 1992; 148(2): 318-23.

36. Wu M, Li J, Gao Q, Ye F. The role of Sema4D/CD100 as a therapeutic target for tumor microenvironments and for autoimmune, neuroimmune and bone diseases. Expert Opin Ther Targets. 2016; 20(7): 885-901.

37. Oinuma I, Ishikawa $Y$, Katoh H, Negishi M. The semaphorin 4D receptor plexin-B1 is a GTPase activating protein for R-ras. Science. 2004; 305(5685): 862-5.

38. Adachi T, Flaswinkel H, Yakura H, Reth M, Tsubata T. Cutting edge: the $\mathrm{B}$ cell surface protein CD72 recruits the tyrosine phosphatase SHP-1 upon tyrosine phosphorylation. J Immunol. 1998; 160(10): 4662-5.

39. Adachi T, Wienands J, Wakabayashi C, Yakura H, Reth M, Tsubata T. SHP-1 requires inhibitory coreceptors to down-modulate $\mathrm{B}$ cell antigen receptormediated phosphorylation of cellular substrates. J Biol Chem. 2001; 276(28): 26648-55.

40. Suzuki K, Kumanogoh A, Kikutani H. Semaphorins and their receptors in immune cell interactions. Nat Immunol. 2008; 9(1): 17-23.

41. Shi W, Kumanogoh A, Watanabe C, Uchida J, Wang $\mathrm{X}$, Yasui T, et al. The class IV semaphorin CD100 plays nonredundant roles in the immune system: defective $\mathrm{B}$ and $\mathrm{T}$ cell activation in CD100-deficient mice. Immunity. 2000; 13(5): 633-42.

42. Hall KT, Boumsell L, Schultze JL, Boussiotis VA, Dorfman DM, Cardoso AA, et al. Human CD100, a novel leukocyte semaphorin that promotes B-cell aggregation and differentiation. Proc Natl Acad Sci U S A. 1996; 93(21): 11780-5.

43. Xue D, Desjardins M, Kaufman GN, Beland M, Al-Tememi S, Ahmed E, et al. Semaphorin 4c: a novel component of B-cell Polarization in Th2-driven immune responses. Front Immunol. 2016; 7: 558. doi: 10.3389/ fimmu.2016.00558.

44. Abbas AK, Lichtman AH, Pillai S. Cellular and molecular immunology. $9^{\text {th }}$ ed. Elsevier. 2017; p. 179207.

45. Kuchroo VK, Umetsu DT, DeKruyff RH, Freeman GJ. The TIM gene family: emerging roles in immunity and disease. Nat Rev Immunol. 2003; 3(6): 454-62.

46. Toyofuku T, Yabuki M, Kamei J, Kamei M, Makino N, Kumanogoh A, et al. Semaphorin 4A, an activator for $\mathrm{T}$ cell mediated immunity, suppresses angiogenesis via Plexin D1. EMBO J. 2007; 26(5): 1373-84.

47. Makino N, Toyofuku T, Takegahara N, Takamatsu $\mathrm{H}$, Okuno $\mathrm{T}$, Nakagawa $\mathrm{Y}$, et al. Involvement of Sema4A in the progression of experimental autoimmune myocarditis. FEBS Lett. 2008; 582(28): 3935-40.

48. Takamatsu H, Okuno T, Kumanogoh A. Regulation of immune cell responses by semaphorins and their receptors. Cell Mol Immunol. 2010; 7(2): 83-8. 
49. Delgoffe GM, Woo S-R, Turnis ME, Gravano DM, Guy C, Overacre AE, et al. Stability and function of regulatory $\mathrm{T}$ cells is maintained by a neuropilin-1semaphorin-4a axis. Nature. 2013; 501(7466): 252-6.

50. Kumanogoh A, Suzuki K, Ch'ng E, Watanabe C, Marukawa S, Takegahara N, et al. Requirement for the lymphocyte semaphorin, CD100, in the induction of antigen-specific $\mathrm{T}$ cells and the maturation of dendritic cells. J Immunol. 2002; 169(3): 1175-81.

51. Watanabe C, Kumanogoh A, Shi W, Suzuki K, Yamada S, Okabe M, et al. Enhanced immune responses in transgenic mice expressing a truncated form of the lymphocyte semaphorin CD100. J Immunol. 2001; 167(8): 4321-8.

52. Witherden DA, Watanabe M, Garijo O, Rieder SE, Sarkisyan G, Cronin SJF, et al. The CD100 receptor interacts with its plexin B2 ligand to regulate epidermal $\gamma \delta \mathrm{T}$ cell function. Immunity. 2012; 37(2): 314-25.

53. Holl EK, Roney KE, Allen IC, Steinbach E, Arthur JC, Buntzman A, et al. Plexin-B2 and Plexin-D1 in dendritic cells: expression and IL-12/IL-23p40 production. PLoS One. 2012; 7(8): e43333.

54. Takegahara N, Takamatsu H, Toyofuku T, Tsujimura T, Okuno T, Yukawa K, et al. Plexin-A1 and its interaction with DAP12 in immune responses and bone homeostasis. Nat Cell Biol. 2006; 8(6): 615-22.

55. Bobolis KA, Moulds JJ, Telen MJ. Isolation of the JMH antigen on a novel phosphatidylinositol-linked human membrane protein. Blood. 1992; 79(6): 1574-81.

56. Yamada A, Kubo K, Takeshita T, Harashima $\mathrm{N}$, Kawano K, Mine T, et al. Molecular cloning of a glycosylphosphatidylinositol-anchored molecule CDw108. J Immunol. 1999; 162(7): 4094-100.

57. Comeau MR, Johnson R, DuBose RF, Petersen M, Gearing $\mathrm{P}$, VandenBos $\mathrm{T}$, et al. A poxvirus-encoded semaphorin induces cytokine production from monocytes and binds to a novel cellular semaphorin receptor, VESPR. Immunity. 1998; 8(4): 473-82.

58. Walzer T, Galibert L, Smedt T De. Poxvirus semaphorin A39R inhibits phagocytosis by dendritic cells and neutrophils. Eur J Immunol. 2005; 35(2): 391-8.

59. Liu H, Juo ZS, Shim AH-R, Focia PJ, Chen X, Garcia KC, et al. Structural basis of semaphorin-plexin recognition and viral mimicry from Sema7A and A39R complexes with PlexinC1. Cell. 2010; 142(5): 749-61.

60. Scott GA, McClelland LA, Fricke AF, Fender A. Plexin $\mathrm{C} 1$, A receptor for semaphorin $7 \mathrm{~A}$, inactivates cofilin and is a potential tumor suppressor for melanoma progression. J Invest Dermatol. 2009; 129(4): 954-63.

61. Xue D, Desjardins M, Mazer BD, Massoud AH, Beland M. Allergic airway inflammation can be regulated by semaphorin $4 \mathrm{c}$ through controlling b-cell migration. J Allergy Clin Immunol. 2014; 133(2): doi.org/10.1016/j. jaci.2013.12.517.

62. Maier V, Jolicoeur C, Rayburn H, Takegahara N, Kumanogoh A, Kikutani H, et al. Semaphorin $4 \mathrm{C}$ and 4G are ligands of Plexin-B2 required in cerebellar development. Mol Cell Neurosci. 2011; 46(2): 419-31.

63. Nishide M, Kumanogoh A. The role of semaphorins in immune responses and autoimmune rheumatic diseases. Nat Rev Rheumatol. 2017; 14(1): 19-31.

64. Kumanogoh A, Kikutani H. Immunological functions of the neuropilins and plexins as receptors for semaphorins. Nat Rev Immunol. 2013; 13(11): 802-14.

65. Worzfeld T, Offermanns S. Semaphorins and plexins as therapeutic targets. Nat Rev Drug Discov. 2014; 13(8): 603-21.

66. Eixarch H, Gutiérrez-Franco A, Montalban X, Espejo C. Semaphorins 3A and 7A: potential immune and neuroregenerative targets in multiple sclerosis. Trends Mol Med. 2013; 19(3): 157-64.

67. Kremer D, Hartung H-P, Küry P. Targeting semaphorins in MS as a treatment strategy to promote remyelination: a tale of mice, rats and men. Mult Scler J. 2015; 21(13): 1616-7.

68. Loma I, Heyman R. Multiple sclerosis: pathogenesis and treatment. Curr Neuropharmacol. 2011; 9(3): 409-16.

69. Syed YA, Hand E, Mobius W, Zhao C, Hofer M, Nave KA, et al. Inhibition of CNS remyelination by the presence of semaphorin 3A. J Neurosci. 2011; 31(10): 3719-28.

70. Piaton G, Aigrot M-S, Williams A, Moyon S, Tepavcevic V, Moutkine I, et al. Class 3 semaphorins influence oligodendrocyte precursor recruitment and remyelination in adult central nervous system. Brain. 2011; 134(4): 1156-67.

71. Smith ES, Jonason A, Reilly C, Veeraraghavan J, Fisher T, Doherty $M$, et al. SEMA4D compromises blood-brain barrier, activates microglia, and inhibits remyelination in neurodegenerative disease. Neurobiol Dis. 2015;73: 254-68.

72. Okuno T, Nakatsuji Y, Kumanogoh A. The role of immune semaphorins in multiple sclerosis. FEBS Lett. 2011; 585(23): 3829-35. 
73. Gutiérrez-Franco A, Eixarch H, Costa C, Gil V, Castillo M, Calvo-Barreiro L, et al. Semaphorin $7 \mathrm{~A}$ as a potential therapeutic target for Multiple Sclerosis. Mol Neurobiol. 2017; 54(6): 4820-31.

74. Nakatsuji Y, Okuno T, Moriya M, Sugimoto T, Kinoshita M, Takamatsu H, et al. Elevation of sema4A implicates Th cell skewing and the efficacy of ifn-b therapy in Multiple Sclerosis. J Immunol. 2012; 188(10): 4858-65.

75. Costa C, Martínez-Sáez E, Gutiérrez-Franco A, Eixarch H, Castro Z, Ortega-Aznar A, et al. Expression of semaphorin $3 \mathrm{~A}$, semaphorin 7A and their receptors in multiple sclerosis lesions. Mult Scler J. 2015; 21(13): 1632-43.

76. Cantó E, Tintoré M, Villar LM, Borrás E, ÁlvarezCermeño JC, Chiva $C$, et al. Validation of semaphorin $7 \mathrm{~A}$ and ala- $\beta$-his-dipeptidase as biomarkers associated with the conversion from clinically isolated syndrome to Multiple Sclerosis. J Neuroinflammation. 2014; 11(1): 181 .

77. Koda T, Okuno T, Takata K, Honorat JA, Kinoshita M, Tada S, et al. Sema4A inhibits the therapeutic effect of IFN- $\beta$ in EAE. J Neuroimmunol. 2014; 268(1-2): 439.

78. Nakatsuji Y. [Sema4A as a biomarker predicting responsiveness to IFN $\beta$ treatment]. Rinsho Shinkeigaku. 2014; 54(12): 972-4.

79. Koda T, Okuno T, Nakatsuji Y, Takata K, Honorat JA, Namba A, et al. Investigation of Sema4A as a biomarker for treatment selection for Multiple Sclerosis. J Neuroimmunol. 2014; 275(1-2): 20-1.

80. Koda T, Namba A, Nakatsuji Y, Niino M, Miyazaki Y, Sugimoto T, et al. Beneficial effects of fingolimod in MS patients with high serum Sema4A levels. PLoS One. 2018; 13(3): e0193986. 